\title{
Safety of Symptomatic Slow-Acting Drugs for Osteoarthritis: Outcomes of a Systematic Review and Meta-Analysis
}

\author{
Germain Honvo ${ }^{1,2}$ (1) Jean-Yves Reginster ${ }^{1,2,3}$ - Véronique Rabenda ${ }^{1,2} \cdot$ Anton Geerinck $^{1,2} \cdot$ Ouafa Mkinsi $^{4}$. \\ Alexia Charles $^{1,2} \cdot$ Rene Rizzoli $^{2,5} \cdot$ Cyrus Cooper $^{2,6,7} \cdot$ Bernard Avouac $^{1} \cdot$ Olivier Bruyère $^{1,2} \mathbb{D}$
}

(C) The Author(s) 2019

\begin{abstract}
Background Symptomatic slow-acting drugs for osteoarthritis (SYSADOAs) are an important drug class in the treatment armamentarium for osteoarthritis (OA).

Objective We aimed to re-assess the safety of various SYSADOAs in a comprehensive meta-analysis of randomized placebocontrolled trials, using, as much as possible, data from full safety reports.

Methods We performed a systematic review and random-effects meta-analyses of randomized, double-blind, placebocontrolled trials that assessed adverse events (AEs) with various SYSADOAs in patients with OA. The databases MEDLINE, Cochrane Central Register of Controlled Trials (Ovid CENTRAL) and Scopus were searched. The primary outcomes were overall severe and serious AEs, as well as AEs involving the following Medical Dictionary for Regulatory Activities (MedDRA) system organ classes (SOCs): gastrointestinal, cardiac, vascular, nervous system, skin and subcutaneous tissue, musculoskeletal and connective tissue, renal and urinary system.

Results Database searches initially identified 3815 records. After exclusions according to the selection criteria, 25 studies on various SYSADOAs were included in the qualitative synthesis, and 13 studies with adequate data were included in the meta-analyses. Next, from the studies previously excluded according to the protocol, 37 with mainly oral nonsteroidal anti-inflammatory drugs (NSAIDs) permitted as concomitant medication were included in a parallel qualitative synthesis, from which 18 studies on various SYSADOAs were included in parallel meta-analyses. This post hoc parallel inclusion was conducted because of the high number of studies allowing concomitant anti-OA medications. Indeed, primarily excluding studies with concomitant anti-OA medications was crucial for a meta-analysis on safety. The decision for parallel inclusion was made for the purpose of comparative analyses. Glucosamine sulfate (GS), chondroitin sulfate (CS) and avocado soybean unsaponifiables (ASU; Piascledine ${ }^{\circledR}$ ) were not associated with increased odds for any type of AEs compared with placebo. Overall, with/without concomitant OA medication, diacerein was associated with significantly increased odds of total AEs (odds ratio [OR] 2.22; 95\% confidence interval [CI] 1.58-3.13; $I^{2}=52.8 \%$ ), gastrointestinal disorders (OR 2.85; 95\% CI $2.02-4.04 ; I^{2}=62.8 \%$ ) and renal and urinary disorders (OR 3.42; 95\% CI 2.36-4.96; $I^{2}=17.0 \%$ ) compared with placebo. In studies that allowed concomitant $\mathrm{OA}$ medications, diacerein was associated with significantly more dermatological disorders (OR 2.47; 95\% CI $1.42-4.31 ; I^{2}=0 \%$ ) and more dropouts due to AEs (OR 3.18; 95\% CI $1.85-5.47 ; I^{2}=13.4 \%$ ) than was placebo. No significant increase in serious or severe AEs was found with diacerein versus placebo.

Conclusions GS and CS can be considered safe treatments for patients with OA. All eligible studies on ASU included in our analysis used the proprietary product Piascledine ${ }^{\circledR}$ and allowed other anti-OA medications; thus, the safety of ASU must be confirmed in future studies without concomitant anti-OA medications. Given the safety concerns with diacerein, its usefulness in patients with OA should be assessed, taking into account individual patient characteristics.
\end{abstract}

\section{Introduction}

Electronic supplementary material The online version of this article (https://doi.org/10.1007/s40266-019-00662-z) contains supplementary material, which is available to authorized users.

Extended author information available on the last page of the article
Osteoarthritis (OA) is a progressive disorder of synovial joints of the hand, knee, and hip that causes pain and limitation of function, increasing disability, and progressive cartilage degeneration [1]. OA occurs frequently in adults aged $>50$ years, with increasing incidence, and is a major 


\section{Key Points}

Our meta-analysis of randomized, placebo-controlled trials did not identify any safety issue associated with glucosamine sulfate (GS) or chondroitin sulfate (CS).

Diacerein is associated with significantly more adverse events than placebo, particularly regarding the gastrointestinal and renal and urinary systems. The usefulness of diacerein for patients with OA should therefore be considered, taking into account its benefit:risk profile according to individual patient characteristics.

Avocado soybean unsaponifiables (ASU) as a whole require further investigation in safety studies without any concomitant anti-OA medication; however, our analyses, which included only the proprietary ASU Piascledine ${ }^{\circledR}$ in studies that allowed concomitant anti-OA medications, seem to support the safety of this product, but this remains to be confirmed.

cause of disability worldwide [1-3]. There is currently no established disease-modifying therapy for OA, so treatment relies on a combination of pharmacologic and non-pharmacologic therapies that can manage OA symptoms, primarily pain and loss of function [4]. Symptomatic slow-acting drugs for osteoarthritis (SYSADOAs) are an important class in the pharmacologic treatment armamentarium for OA that have been demonstrated to alleviate the symptoms of pain and functional impairment, with some additional evidence of a disease-modifying effect in the long term [5-7]. The SYSADOAs class comprises many different agents, including glucosamine, chondroitin, diacerein, and avocado soybean unsaponifiables (ASU), which are supported by varying degrees of clinical efficacy data. Meta-analyses of placebo-controlled trials of SYSADOAs treatment lasting up to 3 years provide evidence that prescription-grade crystalline glucosamine sulfate (GS), chondroitin sulfate (CS), and diacerein have small to moderate beneficial effects in patients with OA [5, 8-10].

The European Society for Clinical and Economic Aspects of Osteoporosis, Osteoarthritis and Musculoskeletal Diseases (ESCEO) recommends the use of SYSADOAs as step 1 pharmacologic background therapy, specifically prescription-grade GS and CS, with paracetamol as add-on rescue analgesia when needed [4]. However, the level of recommendation afforded to SYSADOAs by other international and national guidelines is less favorable, likely because of the multiple products available, including over-the-counter medications and nutritional supplements that contain the active ingredients but for which the pharmaceutical quality is considerably reduced [11-14]. Some issues have been raised in the literature regarding several anti-OA preparations that could not be considered clinically equivalent to their SYSADOA counterparts, which could compromise the efficacy and safety of these products $[15,16]$.

Despite the controversies and non-concordant recommendations about SYSADOAs, they are widely used in many countries as prescription or over-the-counter medications in patients with $\mathrm{OA}[17,18]$. In this context, it is of primary importance to clearly establish their safety profile. In fact, while some SYSADOAs are considered safe for use in patients with OA, some concerns have been raised about the safety profile of other agents. For example, diacerein may induce loose stools or diarrhea as it is incompletely absorbed in the upper gastrointestinal tract [19].

A Cochrane review found significantly more adverse events (AEs) with diacerein than with placebo after 2-36 months; the AEs were mainly diarrhea (relative risk [RR] 3.5; 95\% confidence interval [CI] 2.42-5.11), with an absolute risk increase of $24 \%$ (95\% CI 12-35) and a number needed to treat for an additional harmful outcome (NNTH) of 4 (95\% CI 3-7) [20].

The SYSADOAs GS and CS are generally considered safe medications, with no difference in AEs compared with placebo [6, 7, 21]. Only limited evidence is available on the safety of ASU; however, a meta-analysis of five placebo-controlled trials found no difference in AEs between ASU and placebo [22].

Notably, the meta-analyses that have assessed the safety of SYSADOAs used only published data, and it is well-known that safety data are under-reported in manuscripts. The objective of this study was to re-assess the safety of SYSADOAs in the management of OA in a systematic review and meta-analysis of randomized placebocontrolled trials (RCTs). To better estimate the safety profile of these OA medications, authors of the manuscripts and/or sponsors of studies were contacted to ask for the full report of AEs.

\section{Methods}

The protocol of this systematic review and meta-analysis was previously registered in the PROSPERO database (registration number: CRD42017069875). The systematic review was performed in accordance with the recommendations in the Cochrane Handbook for Systematic Reviews of Interventions [23]. The findings were reported according to PRISMA (Preferred Reporting Items for Systematic Reviews and MetaAnalyses) guidelines [24]. The entire review process (study selection and risk-of-bias assessment) was undertaken using Covidence, the Cochrane platform for systematic reviews. 


\subsection{Eligibility Criteria}

Randomized, double-blind, placebo-controlled, parallelgroup trials that assessed the AEs associated with various SYSADOAs in patients with OA were eligible for inclusion in this meta-analysis. The SYSADOAs considered were limited to GS, CS, hyaluronic acid, collagen derivatives, diacerein, ASU and curcuma, administered orally. The following studies were excluded: crossover studies, reviews or meta-analyses, letters, comments, or editorials. Studies that allowed concomitant anti-OA medications during the trial (other than rescue medication such as paracetamol or aspirin) were also excluded for the main meta-analysis but were kept and used for a parallel analysis.

\subsection{Data Sources and Search Strategies}

A comprehensive literature search was undertaken in the databases MEDLINE (via Ovid), Cochrane Central Register of Controlled Trials (Ovid CENTRAL), and Scopus. Each database was searched from inception up until 31 May 2017. We searched for RCTs of various SYSADOAs in OA, using a combination of study design-, treatment-, and disease-specific keywords and/or medical subject heading (MeSH) terms. While AEs were the outcomes of interest for this study, we decided to avoid the outcome-specific keywords in the search strategies because of the possibility that a study on the efficacy of a drug may have not mentioned terms related to AEs in its title, abstract, or keywords. The search was limited to English and French publications and to human subjects. Detailed search strategies for MEDLINE/ CENTRAL and Scopus databases are reported in the Electronic Supplementary Material (ESM)-1.

Two clinical trials registries, ClinicalTrials.gov (clinicaltrials.gov/) and the World Health Organization's International Clinical Trials Registry Platform Search portal (apps. who.int/trialsearch/) were also checked for trial results that would not have been published. Finally, very recent metaanalyses were also screened for any additional relevant studies. For all studies that responded to the selection criteria, authors of the manuscripts and/or sponsors of studies were automatically contacted to ask for the full report of AEs, as far as there was any way to contact them (email, fax, telephone number or co-author email in another article).

We set up search alerts in the bibliographic databases for any new relevant RCTs that were published from 31 May 2017 until 30 September 2018.

\subsection{Study Selection and Data Extraction}

Two members of the review team (GH and AG) independently evaluated each title and abstract to exclude only obviously irrelevant studies according to the predefined eligibility criteria. At this step, the criteria related to adverse effects were not considered, as studies focusing on the efficacy of a treatment may not report data about adverse effects in the abstract; this means that all trials mentioning only the efficacy information were retrieved at this step. After this first step, the two investigators ( $\mathrm{GH}$ and $\mathrm{AG}$ ) independently reviewed the full text of each of the articles not excluded during the initial screening stage to determine whether the studies met all selection criteria, and those that did not were definitely excluded. All differences of opinion regarding the selection of articles were resolved through discussion and consensus between the two investigators; any persistent disagreement was resolved with the intervention of a third person (VR). A flowchart with the number of included studies at each step was established, including the reasons for excluding studies during the full text reading process.

The full texts of the selected studies were screened for extraction of relevant data using a standard data extraction form. Outcome results data were independently extracted by two investigators of the review team (GH and $\mathrm{AG}$ ). For each study, the following data were extracted: characteristics of the manuscript, trial, patients, disease, and treatments; study objective and design; AEs (outcomes) reported during the trial; and the main conclusion of the study. The raw data (number of events in each group) were extracted for each outcome. The number of patients who experienced at least once any body system-related AE (e.g., nervous system, gastrointestinal system), as well as specific AEs within each body system (e.g., headache, abdominal pain), were extracted. Intention-to-treat (ITT) data were only used when reported or supplied by the study authors or sponsor.

\subsection{Assessment of Risk of Bias in Included Studies}

Two review team members ( $\mathrm{GH}$ and $\mathrm{AG}$ ) independently assessed the risk of bias in each study, using the Cochrane Collaboration's tool for risk of bias assessment [23]. The following characteristics were evaluated:

- Random sequence generation We assessed whether the allocation sequence was adequately generated.

- Allocation concealment We assessed the method used to conceal the allocation sequence, evaluating whether the intervention allocation could have been foreseen in advance.

- Blinding of participants and personnel We assessed the method used to blind study participants and personnel from knowledge of which intervention a participant received and whether the intended blinding was effective.

- Blinding of outcome assessment We assessed the method used to blind outcome assessors from knowledge of which intervention a participant received and whether the intended blinding was effective. 
- Incomplete outcome data We assessed whether participants' exclusions, attrition, and incomplete outcome data were adequately addressed in the paper.

- Selective outcomes reporting We checked whether there was evidence of selective reporting of AEs.

Each item was categorized as having "low" or "high" risk of bias when sufficient information was provided in the manuscript to judge the risk of bias; otherwise, the risk was classed as "unclear." Disagreements were solved by discussion between the two reviewers during a consensus meeting and, when necessary, another member of the review team (VR) was involved for final decision.

\subsection{Outcomes of Interest}

The main system organ classes (SOCs) that are likely to be affected by the use of various SYSADOAs in the treatment of OA were explored in this meta-analysis. The primary outcomes of interest were Medical Dictionary for Regulatory Activities (MedDRA) SOC-related AEs: gastrointestinal, vascular, cardiac, nervous system, skin and subcutaneous tissue, musculoskeletal and connective tissue (MSCT), renal and urinary, and overall severe and serious AEs. Secondary outcomes were withdrawals due to AEs (i.e., the number of participants who stopped the treatment because of an AE) and total AEs (i.e., the number of patients who experienced any $\mathrm{AE}$ at least once).

\subsection{Data Analysis}

Analyses were performed using STATA 14.2 software. We described harms associated with the treatment as odds ratios (OR) with 95\% CIs. We computed an overall effect size for each primary or secondary outcome (AE). Anticipating substantial variability among trial results (i.e., the inter-study variability), we assumed heterogeneity in the occurrence of the AEs, so we planned to use random-effects models for the meta-analyses. We estimated the overall effects and heterogeneity using the DerSimonian and Laird random-effects model [25]. As this method provides biased estimates of the between-study variance with sparse events [26, 27], we also performed the meta-analyses using the restricted maximum likelihood (REML) method [28]. Indeed, we planned in the protocol to use specific methods for rare events analysis if necessary. However, we reported only the results from the DerSimonian and Laird random-effects model, as we found no difference in the effects computed by the two methods. We preferred to report the results obtained with the DerSimonian and Laird method (which uses a correction factor) because it allows for displaying studies with null events on the forest plot, even if those with null event in both the intervention and the control groups are excluded from the overall effect size computation. Conversely, with the REML method, these studies are not displayed on the forest plot. Additionally, the STATA command, which performs the meta-analysis based on the REML method (metaan) has no option for displaying subgroups on the same graphic, unlike the DerSimonian and Laird method command (metan), which has this option ("by").

We tested heterogeneity using Cochran's $Q$ test. As we performed a random-effects meta-analysis, we used the $\mathrm{Tau}^{2}$ estimate as the measure of the between-study variance. The $I^{2}$ statistic was used to quantify heterogeneity, measuring the percentage of total variation across studies due to heterogeneity [29]. In the case of substantial heterogeneity $\left(I^{2}>50 \%\right)$ [30], we prespecified to undertake subgroup analyses, stratifying the analyses according to participants' age in the intervention group, duration of OA complaint, location of OA (knee, hand, hip), number of joints involved, drug dose, duration of treatment, use of bioavailability enhancer, treatment regimen (single use vs. combination), industry involvement (sponsored vs. non-sponsored), nature of the product (pharmaceutical grade vs. food supplement), and risk of bias (e.g., studies with low risk of bias vs. all other studies).

Funnel plot asymmetry was assessed for publication bias by visual inspection and using the test proposed by Harbord et al. [31], which is more suitable for dichotomous outcomes with effects sizes measured as ORs [32] than the classical Egger's test [33]. In the end, we assessed the certainty of each piece of evidence based on the GRADE approach [34] and prepared summary of findings tables using the GRADEpro online software [35].

\subsection{Additional Analysis}

We performed additional post-hoc meta-analyses, in parallel with the main meta-analysis including the studies responding to our pre-defined eligibility criteria. Studies allowing concomitant anti-OA medications, which were excluded based on our eligibility criteria, as well as all studies with or without concomitant anti-OA medications, were considered separately in parallel to the primary meta-analysis. These parallel analyses were conducted according to the same principles described in the data analysis section for the main meta-analysis. However, instead of depicting the results of the parallel analyses in separate forest plots, we prefer to show all the analyses for each outcome on the same figure for ease of comparison. Therefore, considering the rationale of this safety meta-analysis (the exclusion of studies with other anti-OA medication allowed), the parallel analyses on one single forest plot are not to be considered subgroup analyses as for a classical meta-analysis. 


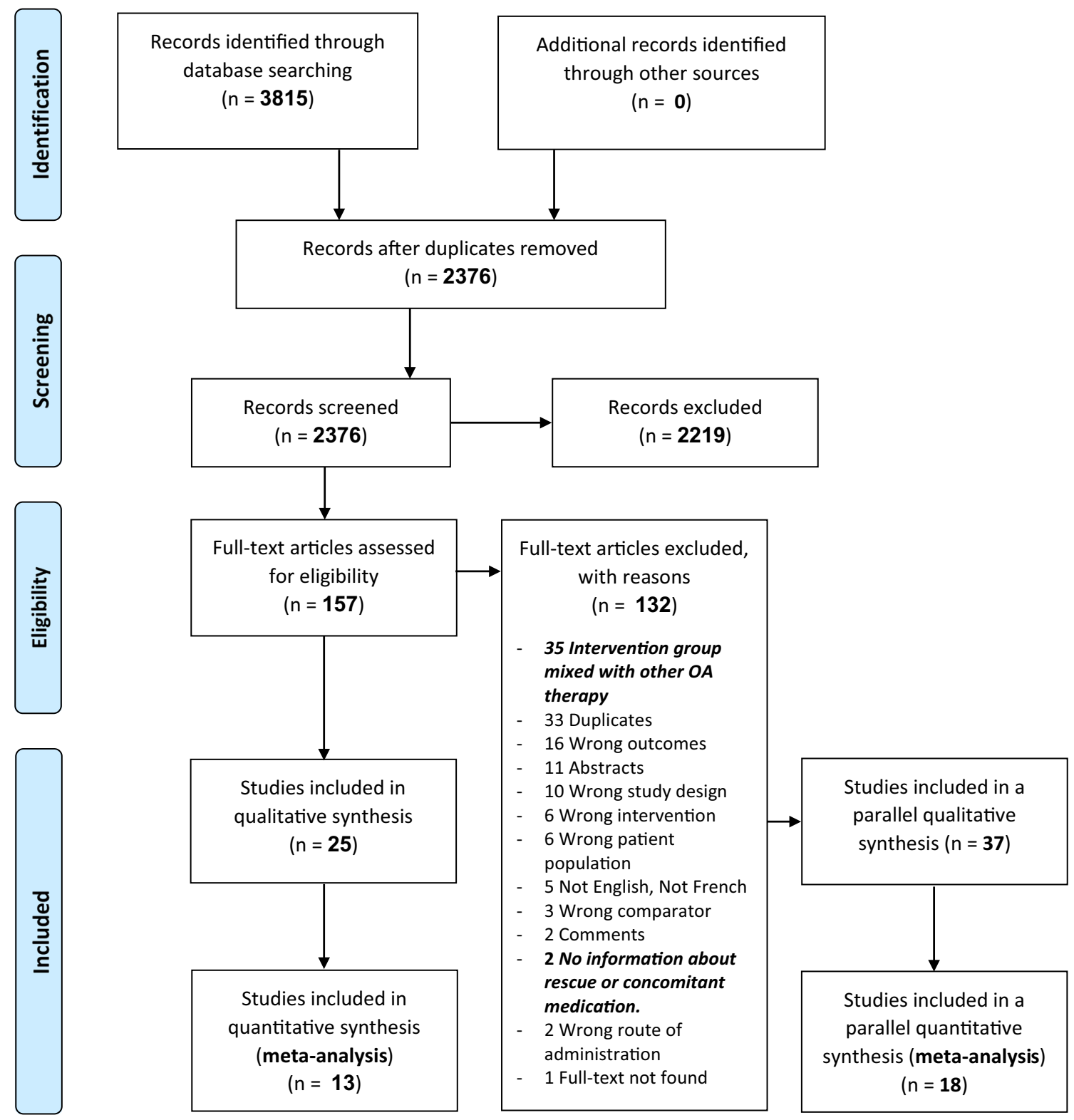

Fig. 1 Flow chart of the study. $O A$ osteoarthritis

\section{Results}

\subsection{Initial Study Selection and Characteristics}

Database searches initially identified 3815 records; after exclusions (Fig. 1), 157 articles were assessed for eligibility. Of these, 132 studies were excluded for various reasons according to the predefined eligibility criteria (Fig. 1). In total, 25 papers were included in the qualitative synthesis according to our prespecified selection criteria, and 13 studies on various SYSADOAs with adequate data were ultimately included in the meta-analysis [36-60]. These studies that met our selection criteria included no concomitant antiOA medication (in accordance with the protocol).

Table 1 presents the characteristics of all the studies included through the systematic review process, according to the predefined selection criteria (those ultimately included in the quantitative synthesis - meta-analysis—are highlighted). The large majority of the studies were in patients with knee $\mathrm{OA}$, with only one including patients with hand OA, one including patients with temporomandibular joint (TMJ) OA, and one involving patients with OA of any joint. In most of the studies, treatment durations varied between 12 and 26 weeks, with the shortest being 4 weeks and the longest 156 weeks. 
Among the 25 articles initially selected for inclusion in this study (from trials without any concomitant antiOA medication), only three had data usable, as published, for the meta-analysis; thus, the risk of selective outcome reporting bias was judged as "high" in $>60 \%$ of these studies. Figures $2 \mathrm{a}$ and $3 \mathrm{a}$ include a summary of the risk of bias assessed for each of the studies included in the primary qualitative synthesis and the risk-of-bias items presented as percentages across all of them. Full data provided by study authors and/or sponsors ultimately enabled us to include 13 studies without any concomitant anti-OA medication in the meta-analyses: five were on GS, six on CS, and two on diacerein. All six studies on CS used the pharmaceuticalgrade products manufactured by IBSA, Institut Biochimique SA. The two studies on diacerein used the pharmaceuticalgrade product manufactured by TRB Chemedica. Only two of the five studies on GS used the pharmaceutical preparation of crystalline GS manufactured by Rottapharm.

\subsection{Post-Hoc Study Selection and Characteristics}

From the 132 studies previously excluded according to the protocol, 37 that permitted other pharmacologic OA treatments or that had no information about rescue or concomitant OA medications (Fig. 1) were included in a post hoc parallel qualitative synthesis, from which 18 studies with adequate data were ultimately included in post hoc parallel meta-analyses [61-97].

We a posteriori decided to consider these studies with other pharmacologic OA treatments in parallel analyses because we were surprised by their number compared with those with no concomitant pharmacologic OA treatment allowed. By doing so, we sought to compare the results from these two groups of studies, knowing that our main conclusions regarding the safety profile of each SYSADOA will primarily be based on the results of the analyses using the studies with no concomitant anti-OA medication (those responding to our prespecified selection criteria). Indeed, as this was a meta-analysis on safety, primarily excluding studies that allowed the use of concomitant anti-OA medications was crucial.

Table 2 presents the characteristics of the studies included in the post hoc parallel qualitative synthesis (those included in the parallel meta-analyses are highlighted). These studies largely involved patients with knee joint OA, as seen in the studies with no concomitant anti-OA medication. Conversely, the studies in the parallel qualitative synthesis included more long-term trials (12 studies [32\%] with treatment duration $\geq 104$ weeks) than the previous studies (4\%). Oral nonsteroidal anti-inflammatory drugs (NSAIDs) were the most permitted concomitant medications.
Harms-related data were relatively well reported in only eight studies, sufficient that they could be used for the analyses. Ultimately, in addition to the full data provided by study authors and/or sponsors, we could perform parallel post hoc meta-analyses for GS (four studies), CS (six studies), diacerein (four studies), and ASU (four studies). All the included studies on ASU used the pharmaceutical-grade proprietary product Piascledine ${ }^{\circledR}$ (Expanscience). The raw data sent by study authors and/or sponsors resulted in a substantial decrease of the impact of selective outcome reporting bias in the studies included in the parallel meta-analyses. In fact, for 17 of the 18 studies included in these analyses, the data used were those sent by the study authors and/or sponsors. Originally, almost $70 \%$ of the studies included in the parallel qualitative synthesis were associated with a "high" risk of selective outcome reporting bias. Figures $2 b$ and $3 b$ include a summary of the risk of bias assessed for each study included in the parallel qualitative synthesis and the risk-ofbias items presented as percentages across all these studies.

\subsection{Glucosamine Sulfate}

For the primary outcomes, with or without concomitant antiOA medications, there was no significant increase in the odds for any SOC-related disorders investigated (gastrointestinal, cardiac, vascular, nervous system, dermatological, MSCT, renal and urinary) with GS compared with placebo, as well as for severe and serious AEs (ESM-2).

Likewise, for the secondary outcomes, there was no significant increase in odds for total AEs reported with GS versus placebo (OR $0.96 ; 95 \%$ CI $0.66-1.41 ; I^{2}=29.8 \%$ ) (overall OR) (Fig. 4). In both studies with and those without concomitant anti-OA medications, as well as overall, there were no more withdrawals due to AEs with GS compared with placebo (ESM-2).

\subsection{Chondroitin Sulfate}

With or without concomitant anti-OA medications, there was no significant increase in the odds with CS versus placebo for any SOC-related disorders investigated or for severe and serious AEs and withdrawals due to AEs (ESM-2). Conversely, fewer AEs pertaining to the renal and urinary system were reported with CS than with placebo, whatever the group of studies considered; these findings reached statistical significance overall (OR 0.40; 95\% CI 0.22-0.74) and in studies with concomitant anti-OA medications (OR 0.43; 95\% CI 0.23-0.81) (ESM-2).

In studies with no concomitant OA medications allowed, patients receiving $\mathrm{CS}$ were significantly less likely to report AEs (total AEs) than were those receiving placebo (OR $0.70 ; 95 \%$ CI $0.51-0.98 ; I^{2}=33.3 \%$ ). The same trend was observed in studies with concomitant OA medications 


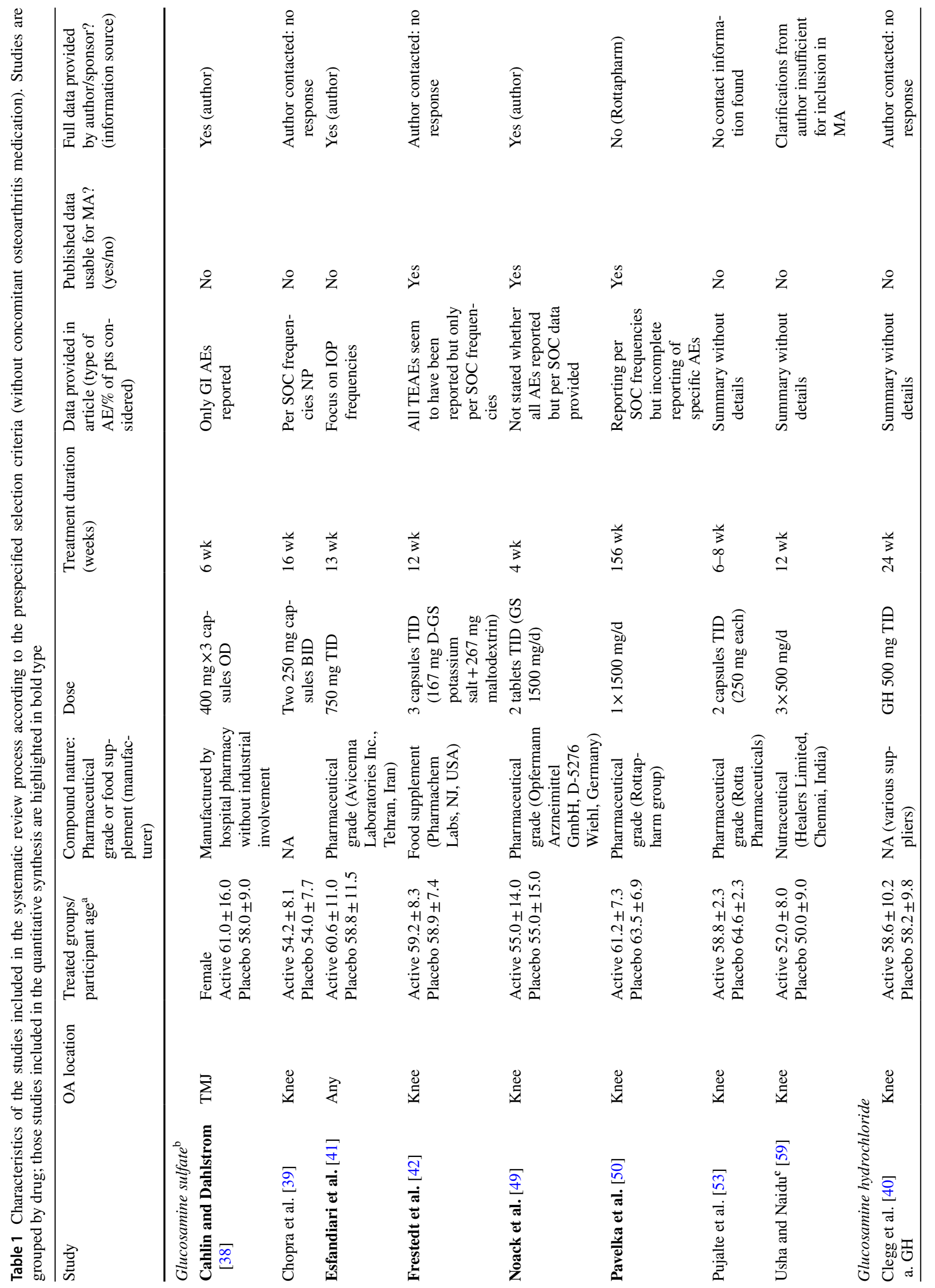




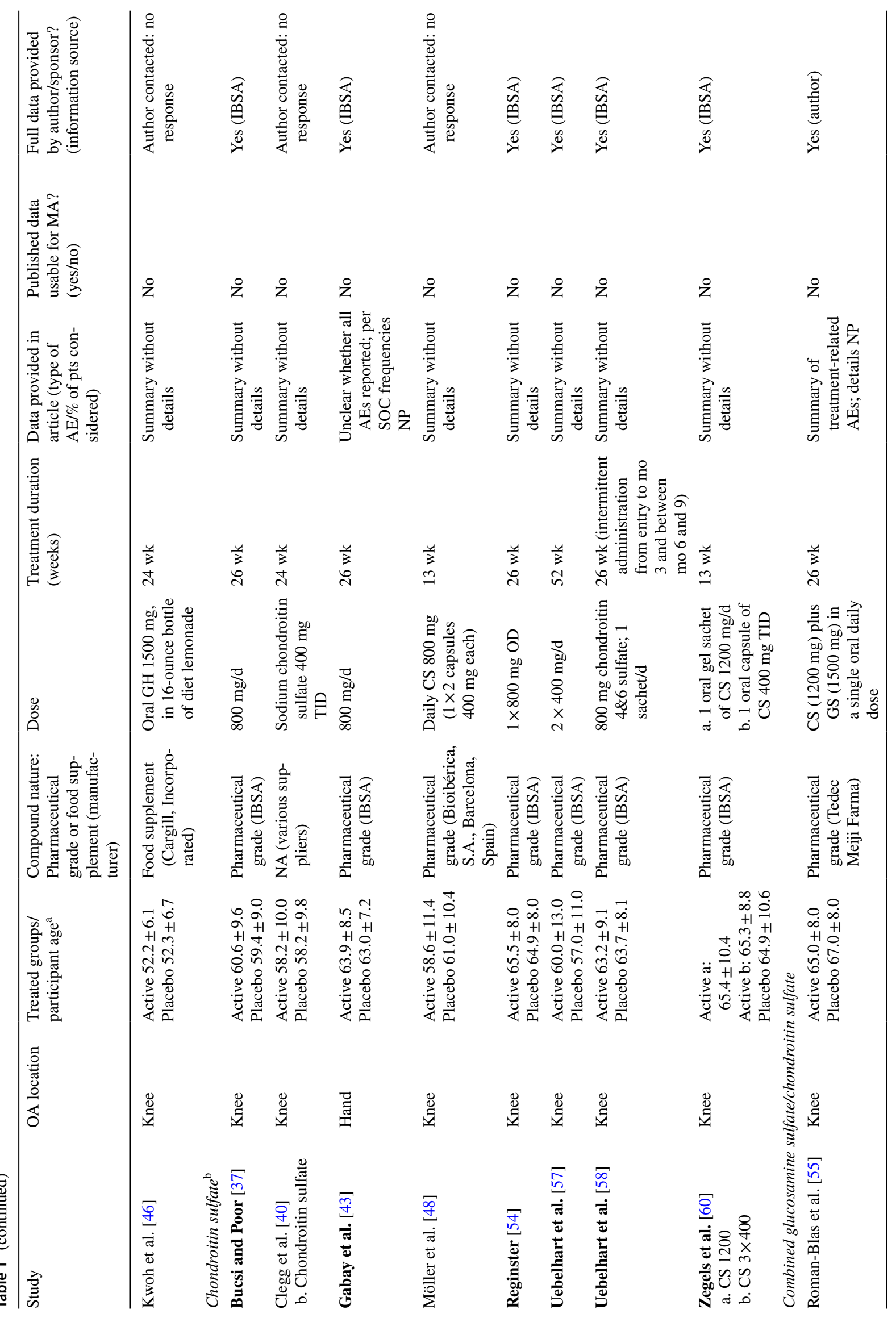




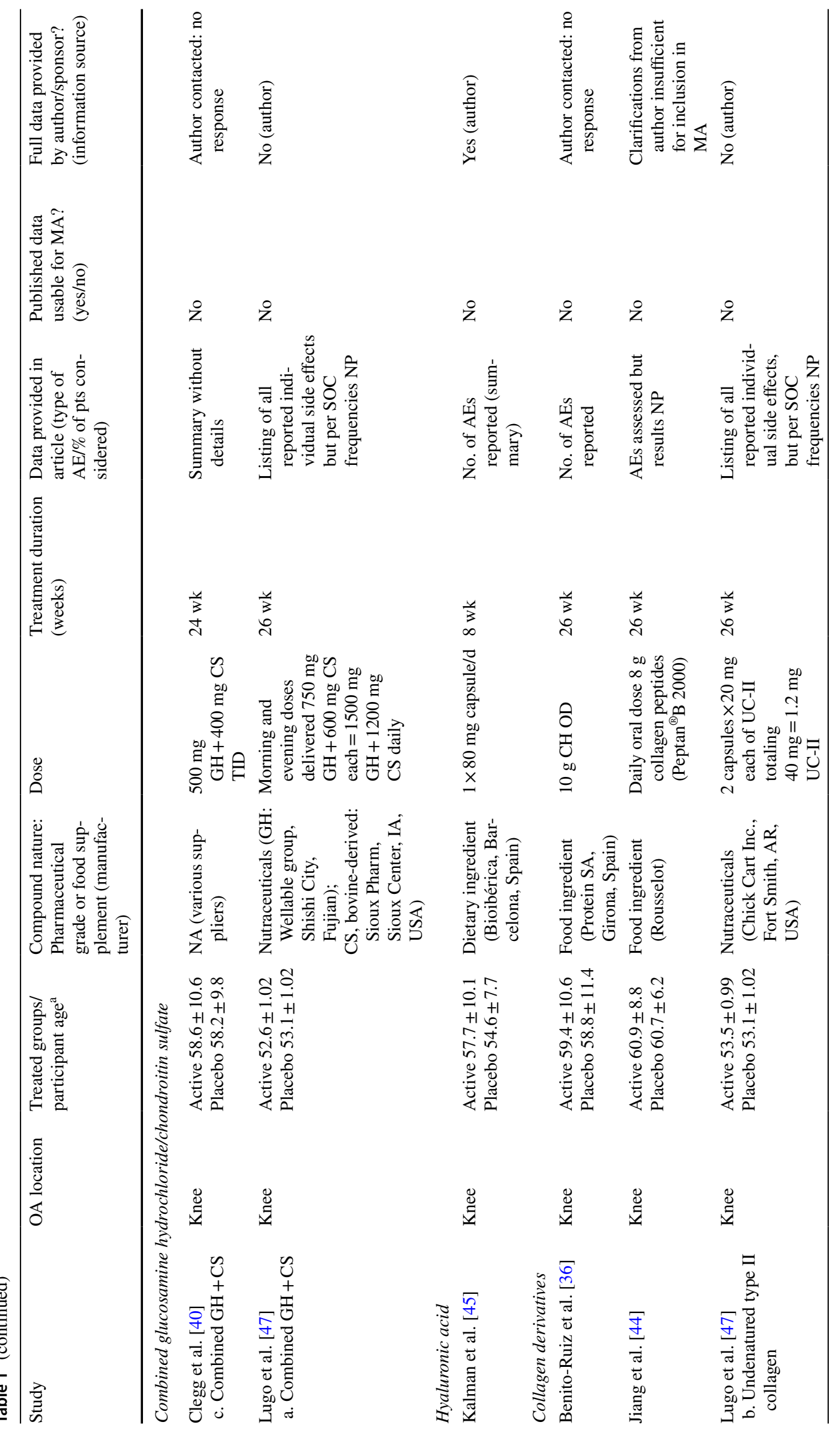




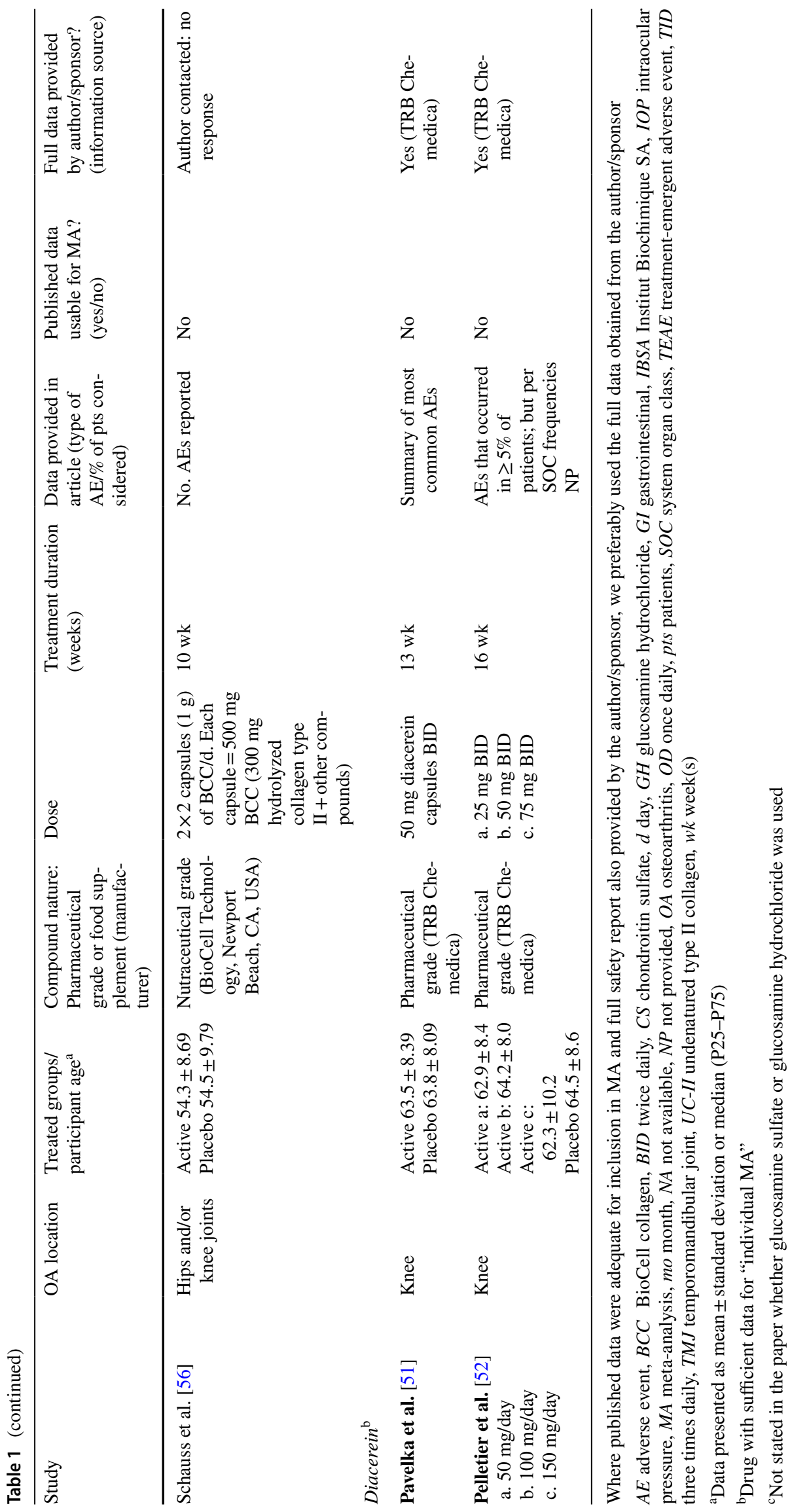


Fig. 2 a Summary of risk of bias in studies without any concomitant anti-osteoarthritis medication (studies meeting prespecified selection criteria): review authors' judgements about each risk-of-bias item for each study included in the initial qualitative synthesis. b Risk-of-bias summary in studies with concomitant anti-osteoarthritis medication (studies included in the post hoc parallel qualitative synthesis): review authors' judgements about each risk-of-bias item for each study included in the parallel qualitative synthesis. $O A$ osteoarthritis

\begin{tabular}{|c|c|c|c|c|c|c|}
\hline (A) & 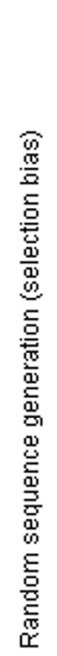 & 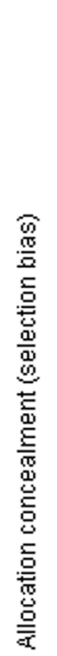 & 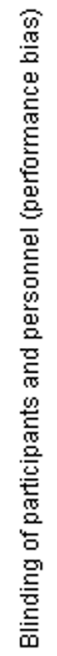 & 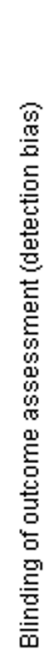 & 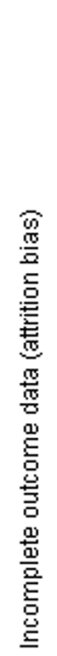 & 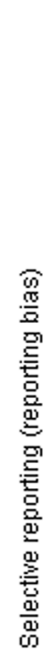 \\
\hline Benito Ruiz 2009 & $?$ & $?$ & $?$ & $?$ & $?$ & \\
\hline Bucsi 1998 & $?$ & $?$ & + & $?$ & + & \\
\hline Cahlin 2011 & + & - & + & + & 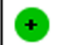 & \\
\hline Chopra 2011 & + & $\oplus$ & + & + & $\oplus$ & + \\
\hline Clegg 2006 & $\odot$ & $\oplus$ & $\oplus$ & + & $?$ & \\
\hline Esfandiari 2017 & $\oplus$ & $\oplus$ & + & $?$ & + & \\
\hline Frestedt 2008 & + & 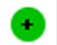 & $\odot$ & + & + & + \\
\hline Gabay 2011 & 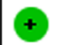 & 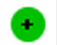 & + & + & + & + \\
\hline Jiang 2014 & $?$ & $?$ & $?$ & $?$ & - & \\
\hline Kalman 2008 & $\oplus$ & $?$ & $\odot$ & + & - & + \\
\hline Kwoh 2014 & + & $\oplus$ & + & + & + & \\
\hline Lugo 2016 & 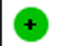 & 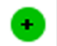 & $\odot$ & + & - & + \\
\hline Moller 2010 & + & $?$ & + & + & $?$ & \\
\hline Noack 1994 & $?$ & $?$ & $\odot$ & + & + & + \\
\hline Pavelka 2002 & + & + & + & + & + & + \\
\hline Pavelka 2007 & + & $?$ & + & + & + & \\
\hline Pelletier 2000 & + & + & $?$ & $?$ & + & \\
\hline Pujalte 1980 & ? & ? & + & $?$ & - & + \\
\hline Reginster 2017 & ? & ? & + & $?$ & + & \\
\hline Roman Blas 2017 & + & + & + & + & - & \\
\hline Schauss 2012 & + & + & + & + & - & + \\
\hline Uebelhart 1998 & $?$ & $?$ & + & $?$ & $?$ & \\
\hline Uebelhart 2004 & + & + & + & + & & \\
\hline Usha 2004 & + & ? & + & $?$ & + & \\
\hline Zegels 2013 & $\odot$ & $?$ & + & $?$ & + & \\
\hline
\end{tabular}

\begin{tabular}{|c|c|c|c|c|c|c|}
\hline \multicolumn{2}{|r|}{ 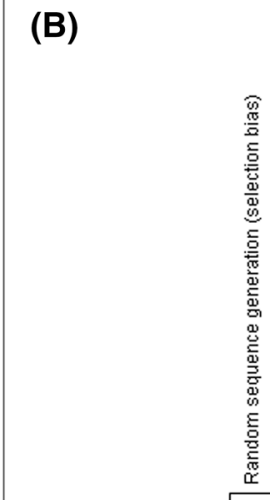 } & 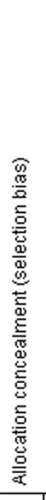 & 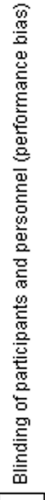 & 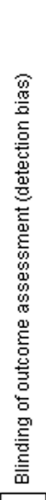 & 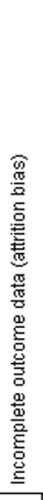 & 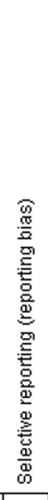 \\
\hline Appelboom 2001 & $?$ & $?$ & $?$ & $?$ & $\odot$ & 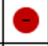 \\
\hline Blotman 1997 & $?$ & $?$ & $?$ & $?$ & + & + \\
\hline Bourgeois 1998 & ? & $?$ & $?$ & $?$ & $\odot$ & $\theta$ \\
\hline Cibere 2004 & + & $\oplus$ & 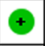 & + & $\odot$ & $\theta$ \\
\hline Das 2000 & $\odot$ & $\odot$ & $\odot$ & + & + & $\odot$ \\
\hline Dougados 2001 & 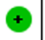 & $\odot$ & $\odot$ & $?$ & $\odot$ & $\theta$ \\
\hline Drovanti 1980 & $?$ & $?$ & $?$ & ? & $\odot$ & $\odot$ \\
\hline Fransen 2015 & 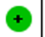 & $\odot$ & ๑ & $\odot$ & $?$ & $\theta$ \\
\hline Giordano 2009 & $\odot$ & $?$ & - & + & $\odot$ & $\theta$ \\
\hline Herrero Beaumant 2007 & + & 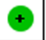 & + & + & - & $\theta$ \\
\hline Hughes 2002 & + & (†) & ๑) & + & $?$ & 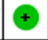 \\
\hline Kahan 2009 & 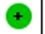 & $\odot$ & + & + & $\odot$ & $\theta$ \\
\hline Kumar 2014 & 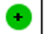 & $?$ & ? & ? & $\odot$ & $\theta$ \\
\hline Lequesne 1998 & $?$ & $?$ & $?$ & ? & $\odot$ & $\theta$ \\
\hline Lequesne 2002 & $\odot$ & $\odot$ & $\odot$ & $\odot$ & $\odot$ & $\theta$ \\
\hline Maheu 1998 & 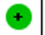 & $\odot$ & ? & $?$ & $\odot$ & $\odot$ \\
\hline Maheu 2014 & + & + & $\odot$ & $?$ & + & - \\
\hline Mathieu 2002 & ? & $?$ & $?$ & + & $\odot$ & $\theta$ \\
\hline Mazieres 1992 & $?$ & $?$ & $?$ & $?$ & - & $\odot$ \\
\hline Mazieres 2001 & $?$ & $?$ & $\odot$ & + & $?$ & $\theta$ \\
\hline Mazieres 2007 & $\odot$ & ? & $\odot$ & $\odot$ & $\odot$ & - \\
\hline McAlindon 2011 & $\odot$ & $\odot$ & $\odot$ & $\odot$ & $?$ & O \\
\hline Michel 2005 & $\odot$ & $\odot$ & $\odot$ & + & $\odot$ & ○ \\
\hline Nakagawa 2014 & ? & $?$ & $?$ & $?$ & $?$ & $\theta$ \\
\hline Nguyen 1994 & $?$ & ๑ & $?$ & $?$ & $\odot$ & + \\
\hline Panahi 2014 & ? & $?$ & + & $?$ & - & $\theta$ \\
\hline Pham 2004 & $\odot$ & $\odot$ & $\odot$ & $\odot$ & $\odot$ & $\theta$ \\
\hline Railhac 2012 & $\odot$ & $?$ & ? & $?$ & $\odot$ & - \\
\hline Reginster 2001 & $\odot$ & $\odot$ & $\odot$ & $?$ & $\odot$ & - \\
\hline Rindone 2000 & $\odot$ & $?$ & $?$ & ? & - & - \\
\hline Rozendaal 2008 & $\odot$ & $\odot$ & + & + & $\odot$ & $\odot$ \\
\hline Shin 2013 & 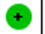 & + & ? & $?$ & $\odot$ & $\odot$ \\
\hline Srivastava 2016 & 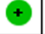 & $?$ & $?$ & $?$ & + & 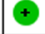 \\
\hline Stančík 2012 & $?$ & $?$ & $?$ & $?$ & $?$ & $\theta$ \\
\hline Vignon 2002 & $?$ & $?$ & $?$ & $?$ & $\odot$ & - \\
\hline Wildi 2011 & ? & $\odot$ & ? & $?$ & $\odot$ & $\odot$ \\
\hline Zenk 2002 & $\odot$ & $\odot$ & $\odot$ & $\odot$ & $\odot$ & $\odot$ \\
\hline
\end{tabular}


Fig. 3 a Risk-of-bias graph in studies without any concomitant anti-osteoarthritis medication: review authors' judgements about each risk-of-bias item presented as percentages across all studies included in the initial qualitative synthesis. b Risk-of-bias graph for studies with concomitant anti-osteoarthrits medication: review authors' judgements about each risk-of-bias item presented as percentages across all studies included in the parallel qualitative synthesis
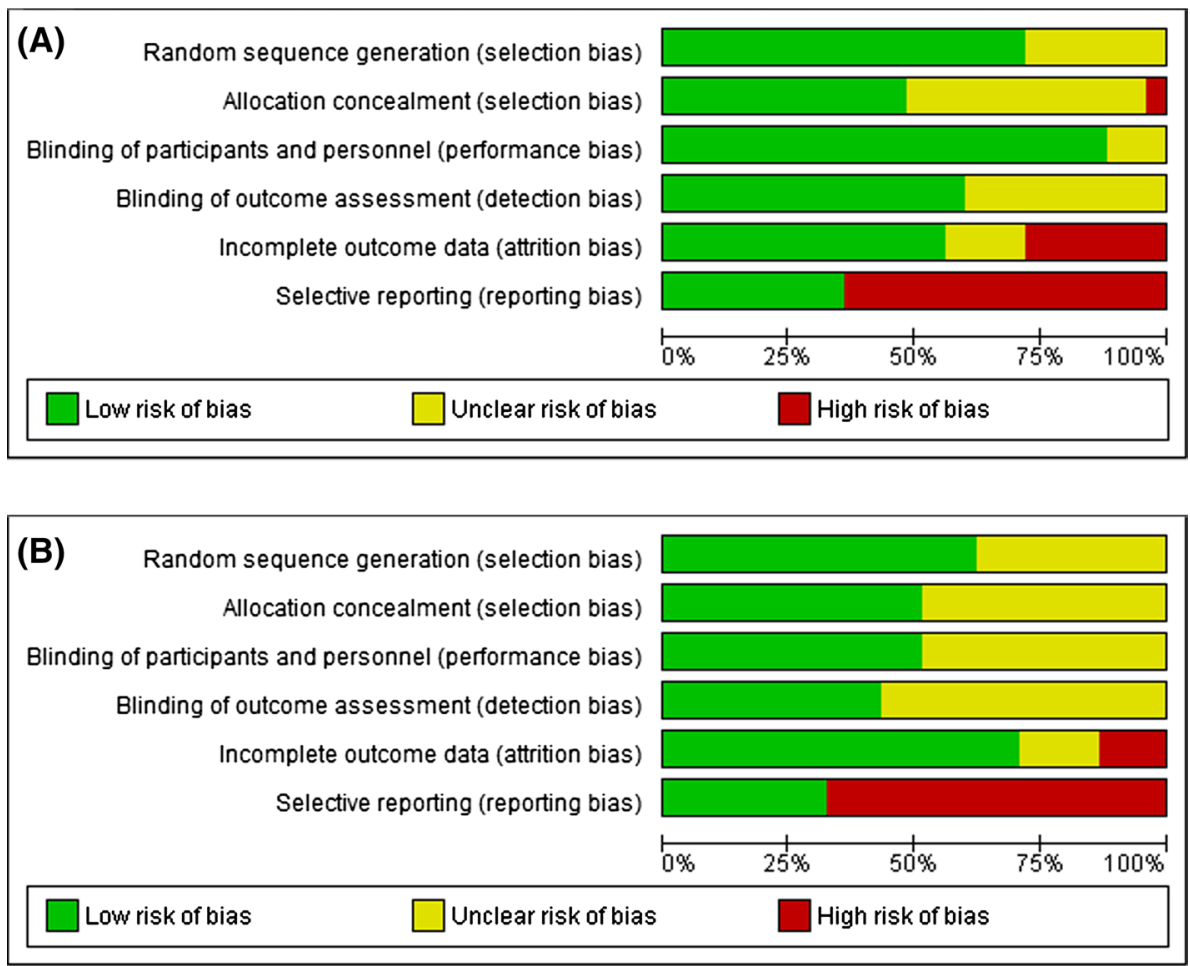

permitted, and overall, but this did not reach statistical significance (Fig. 5).

\subsection{Avocado Soybean Unsaponifiables}

No statistically significant difference was found between ASU treatment and placebo for any SOC-related disorder investigated or for severe and serious AEs and withdrawals due to AEs (ESM-2).

All ASU studies allowed concomitant oral NSAIDs during the trials (Table 2). Using data from these trials, ASU was no more likely than placebo to be associated with AEs (total AEs) (OR 1.09; 95\% CI 0.81-1.46; $I^{2}=0 \%$ ) (Fig. 6).

\subsection{Diacerein}

Significantly more gastrointestinal disorders were reported with diacerein than with placebo (OR 2.85; 95\% CI $2.02-4.04 ; I^{2}=62.8 \%$ ), whether concomitant OA medications were allowed in the treatment protocol (OR 3.25; 95\% CI $\left.2.05-5.16 ; I^{2}=51.3 \%\right)$ or not (OR $2.53 ; 95 \%$ CI $1.43-4.46 ; I^{2}=73.6 \%$ ) (Fig. 7). Diarrhea, abdominal pain, soft stools, and colitis were the most frequently reported gastrointestinal AEs.

The odds of nervous system disorders (mostly dizziness) were significantly increased with diacerein but only among studies that did not allow concomitant pharmacologic OA treatment (OR 3.46; 95\% CI 1.44-8.32; $I^{2}=0 \%$ ) (Fig. 8).

Significantly increased odds of skin and subcutaneous tissue disorders were reported with diacerein in studies that allowed concomitant OA medications (OR 2.47; 95\% CI $1.42-4.31 ; I^{2}=0.0 \%$ ), with eczema, rash, pruritus, and urticaria being the most reported specific events. There were also more skin and subcutaneous tissue disorders with diacerein than with placebo in studies that did not allow concomitant OA medications, but this did not reach statistical significance (Fig. 9).

The odds of having renal and urinary disorders was significantly increased with diacerein versus placebo (OR 3.42 ; 95\% CI 2.36-4.96; $I^{2}=17.0 \%$ ), whether concomitant OA medications were used (OR 3.40; 95\% CI 1.18-9.82; $\left.I^{2}=68.2 \%\right)$ or not (OR 3.16; 95\% CI $\left.1.93-5.15 ; I^{2}=0.0 \%\right)$ (Fig. 10). Urine discoloration and urinary tract infection were the most frequently reported specific AEs.

A reduced odds of MSCT disorders was observed with diacerein versus placebo when concomitant OA medications were not allowed during the trials (OR 0.53; 95\% CI $\left.0.35-0.82 ; I^{2}=2.2 \%\right)$. This was not observed when concomitant OA medications were allowed (OR 1.19; 95\% CI $\left.0.82-1.73 ; I^{2}=0 \%\right)($ ESM-2).

Overall, and specifically in studies with or without concomitant OA medications, there were no increased odds of serious and severe AEs with diacerein compared with placebo (ESM-2). 


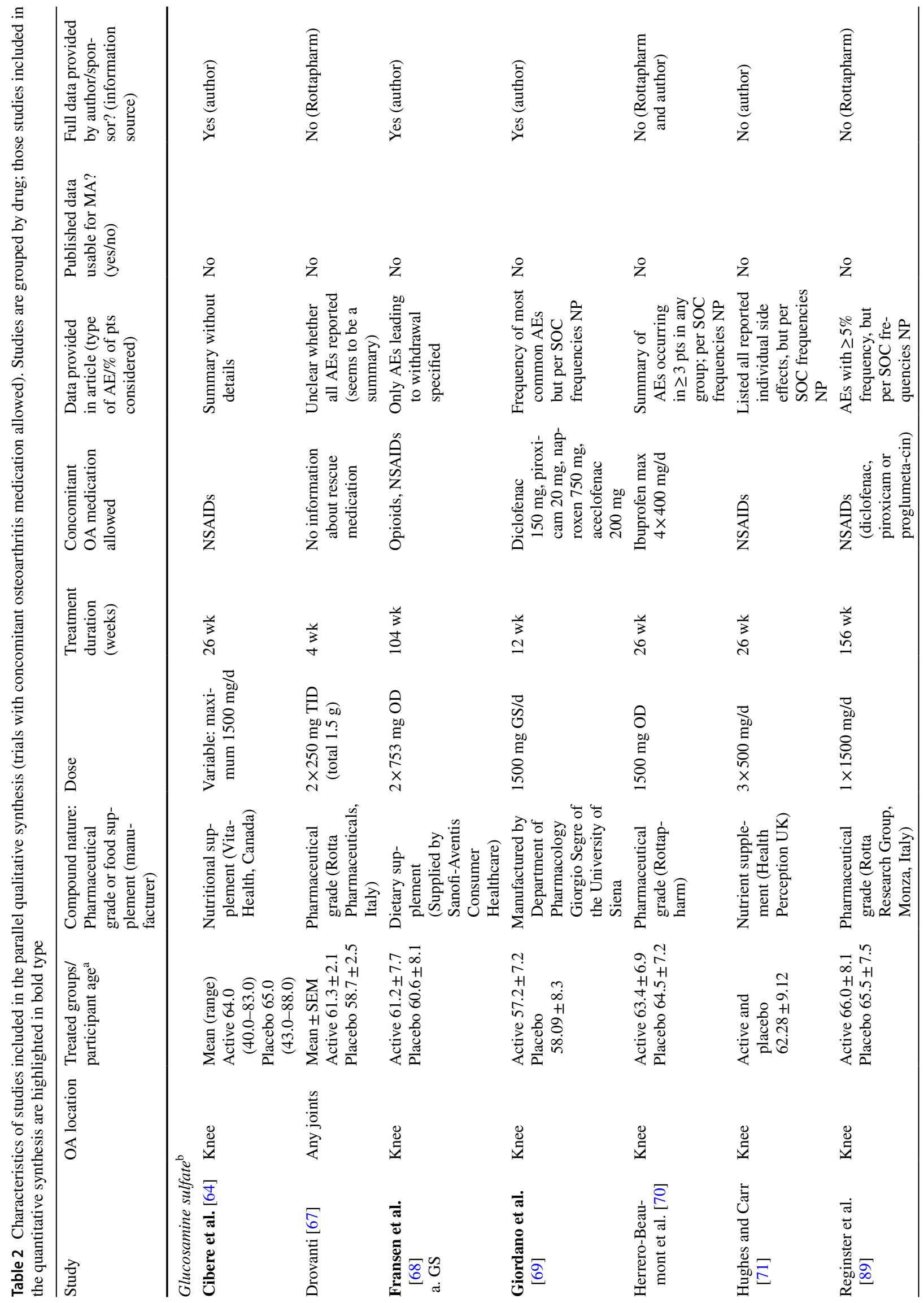




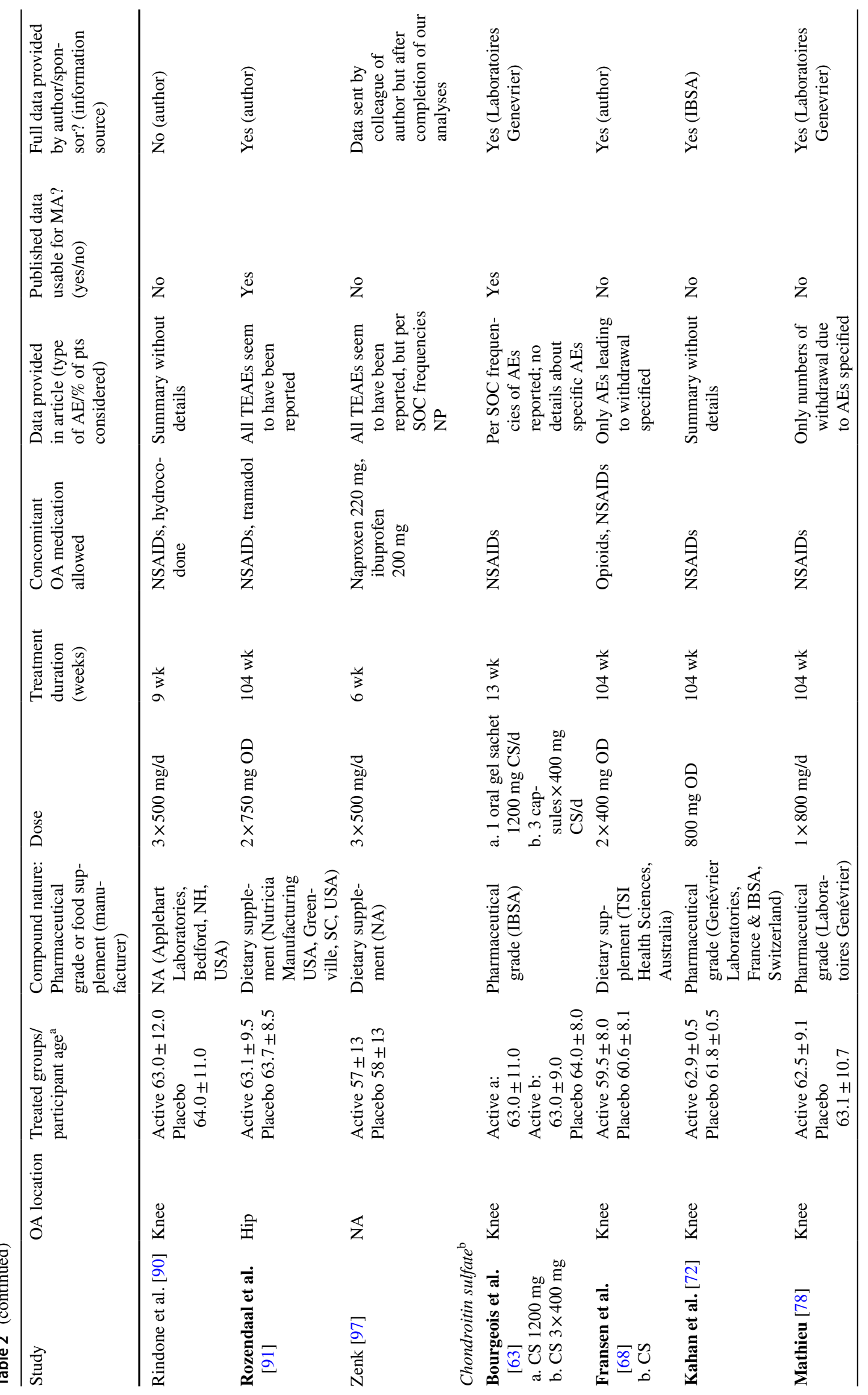




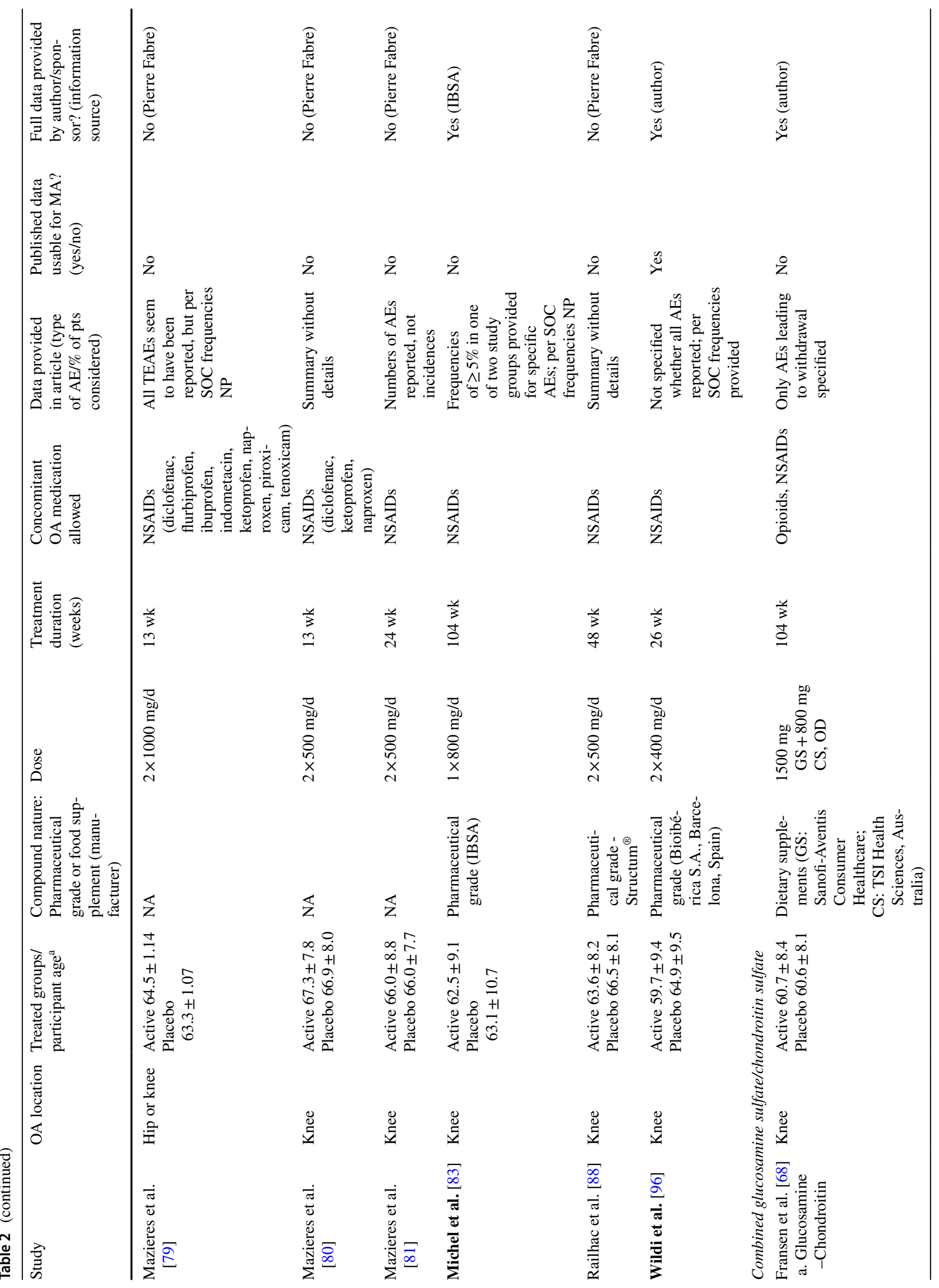




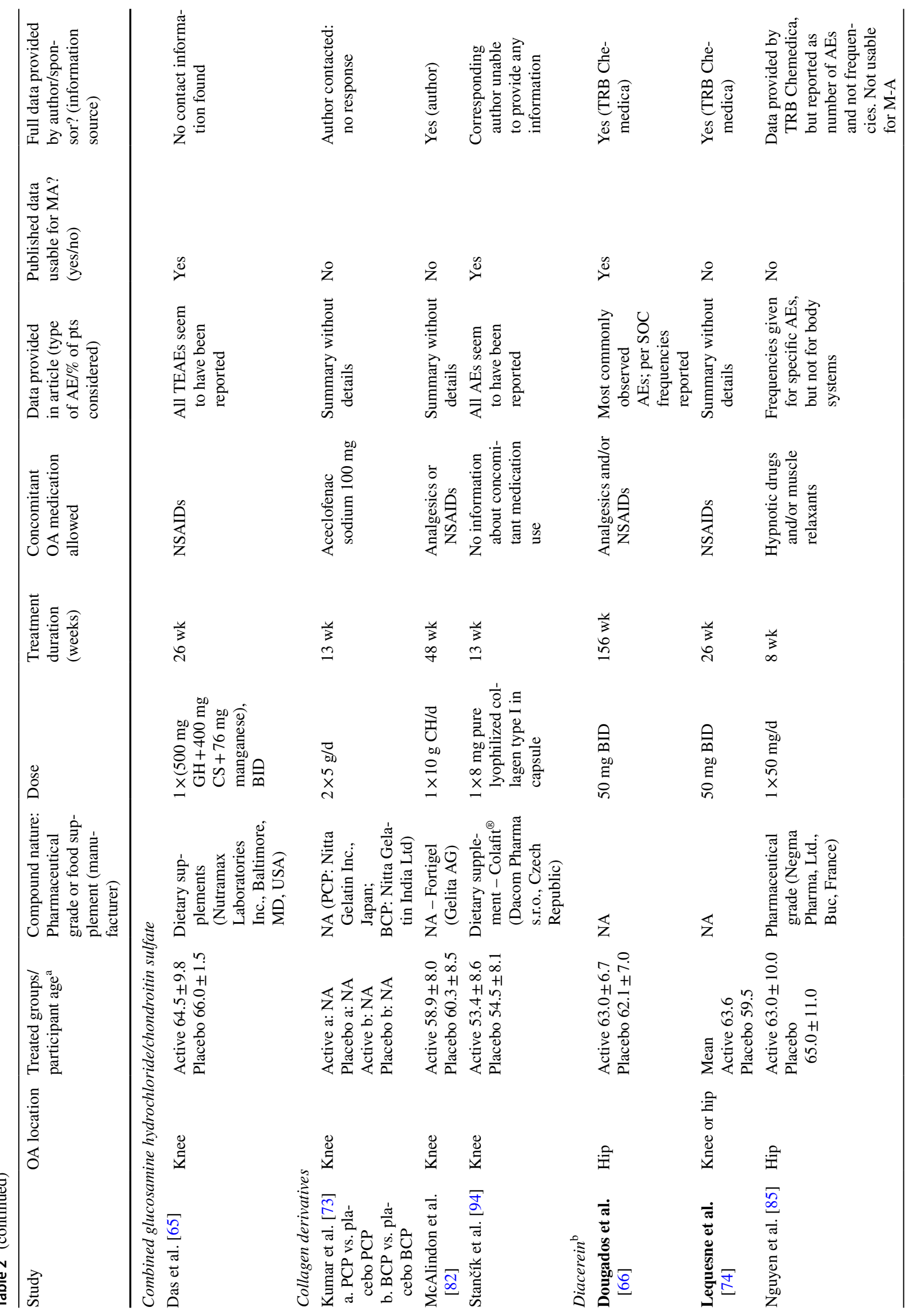




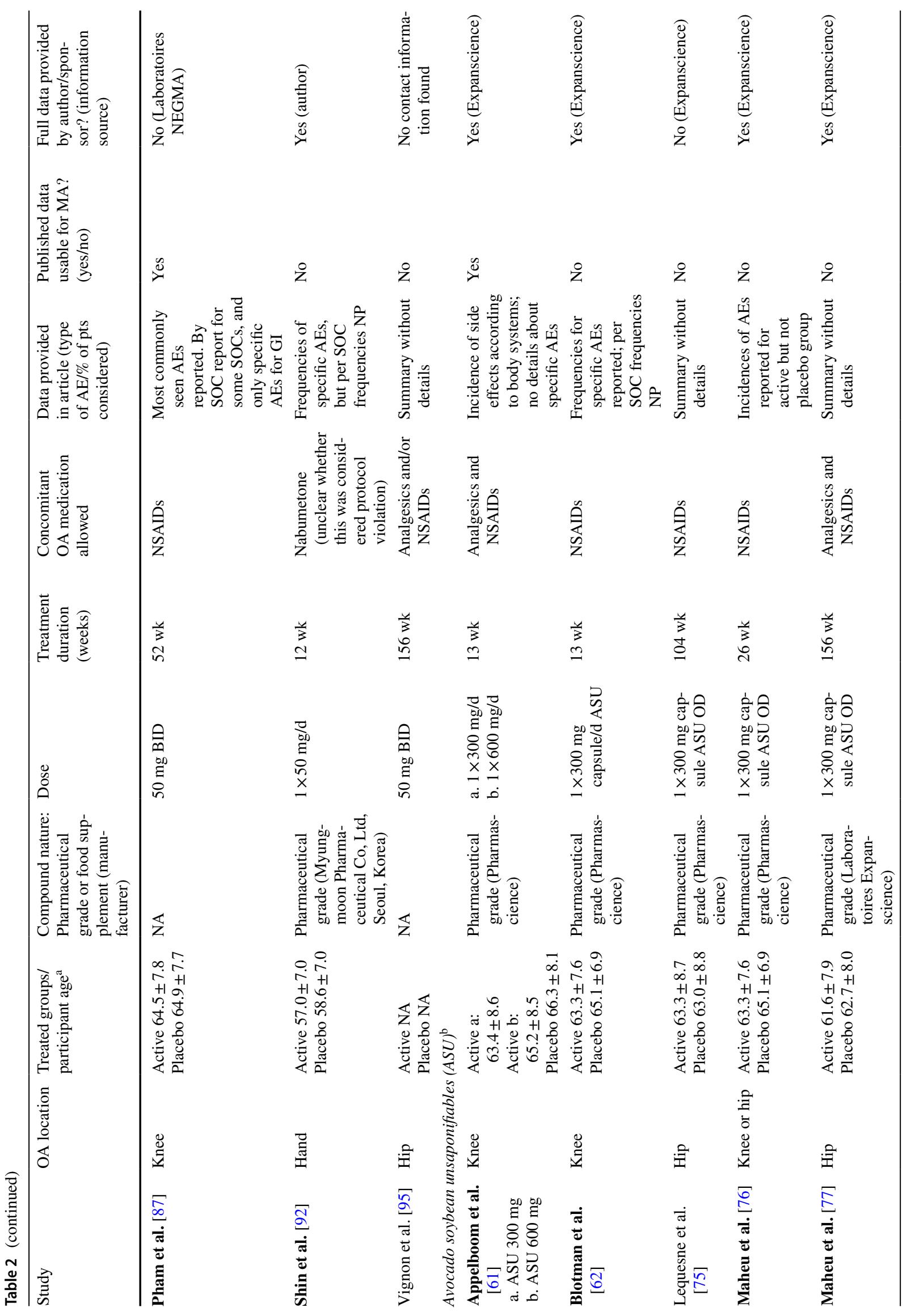




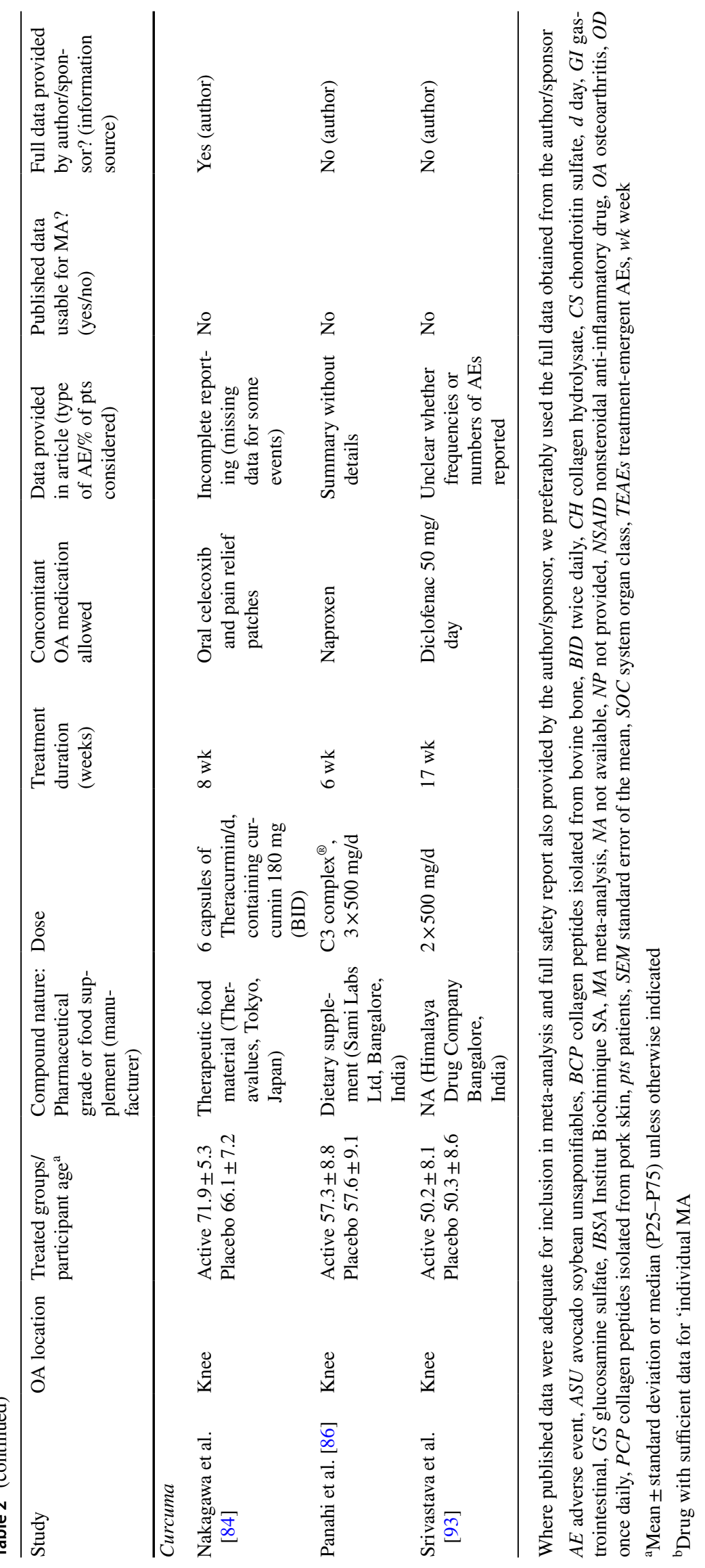


Glucosamine sulfate: Any adverse event

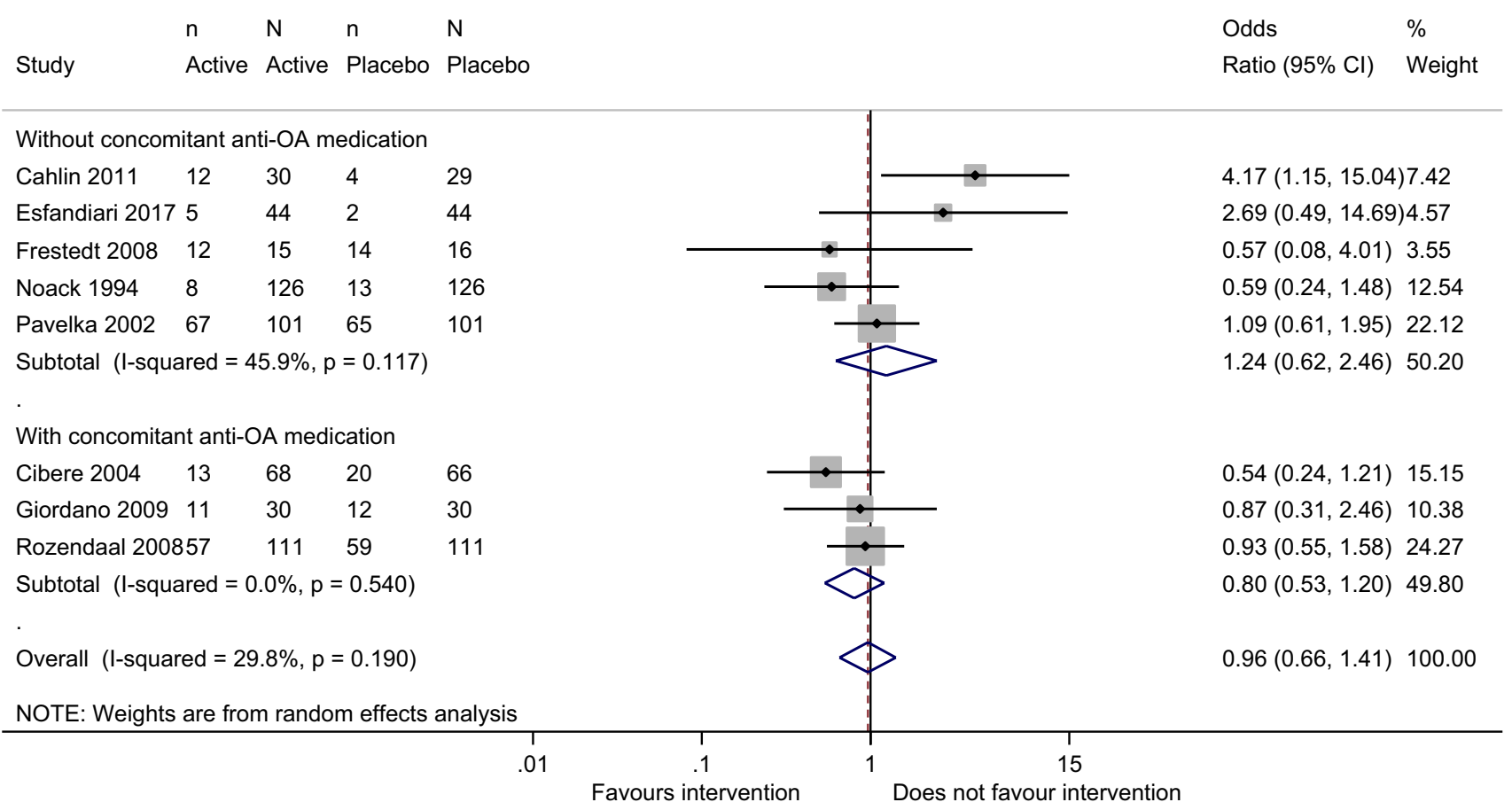

Fig. 4 Forest plot displaying the results of the meta-analyses comparing total adverse events with glucosamine sulfate versus placebo in patients with osteoarthritis: overall analysis and analyses of studies with and without concomitant anti-OA medication allowed. $C I$ confidence interval, $O A$ osteoarthritis

funnel plots for "total AEs" are depicted in Fig. 13. All the other funnel plots are provided in ESM-3.

\subsection{GRADE Assessment of Findings}

Using the GRADE approach [34], we assessed the certainty of evidence for each of the outcomes for GS, CS, ASU, and diacerein. Overall, for all of the outcomes considered for CS, ASU, and diacerein, the certainty of evidence was "high." For diacerein, this was downgraded to "moderate" for a few outcomes in studies with or without concomitant antiOA medications (data not shown), because of the large CIs around the estimates. We found "moderate" certainty of evidence for severe and serious AEs with GS (overall) and for some other outcomes in studies with or without concomitant anti-OA medications (data not shown) because of wide CIs (imprecision) due to the low number of events (null events were reported in most of the included studies); for other outcomes, the certainty of evidence was "high" with GS. The detailed results for the main outcomes for each of these compounds are depicted in the summary of findings tables using data from "overall" meta-analyses (Tables 3, 4, 5, 6). 


\section{Chondroitin sulfate: Any adverse event}

\begin{tabular}{|c|c|c|c|c|c|c|c|c|}
\hline Study & $\begin{array}{l}\mathrm{n} \\
\text { Active }\end{array}$ & $\begin{array}{l}\mathrm{N} \\
\text { Active }\end{array}$ & $\begin{array}{l}\mathrm{n} \\
\text { Placebo }\end{array}$ & $\begin{array}{l}\mathrm{N} \\
\text { Placebo }\end{array}$ & & & Odds Ratio $(95 \% \mathrm{Cl}$ & $\begin{array}{l}\% \\
\text { )Weight }\end{array}$ \\
\hline \multicolumn{9}{|c|}{ Without concomitant anti-OA medication } \\
\hline Bucsi 1998 & 2 & 39 & 3 & 46 & & & $0.77(0.12,4.89)$ & 2.09 \\
\hline Gabay 2011 & 34 & 81 & 34 & 82 & & & $1.02(0.55,1.90)$ & 10.47 \\
\hline Reginster 2017 & 100 & 199 & 110 & 205 & $\rightarrow$ & & $0.87(0.59,1.29)$ & 15.27 \\
\hline Uebelhart 1998 & 1 & 21 & 3 & 21 & & & $0.30(0.03,3.15)$ & 1.33 \\
\hline Uebelhart 2004 & 8 & 54 & 6 & 56 & & $\rightarrow$ & $1.45(0.47,4.49)$ & 4.77 \\
\hline Zegels 2013 (a) & 61 & 117 & 84 & 117 & $\rightarrow$ & & $0.43(0.25,0.74)$ & 11.98 \\
\hline Zegels 2013 (b) & 68 & 119 & 84 & 117 & $\rightarrow+1$ & & $0.52(0.30,0.90)$ & 11.97 \\
\hline \multicolumn{5}{|c|}{ Subtotal $(I-$ squared $=33.3 \%, p=0.174)$} & & & $0.70(0.51,0.98)$ & 57.88 \\
\hline \multicolumn{9}{|c|}{ With concomitant anti-OA medication } \\
\hline \multirow{2}{*}{\multicolumn{2}{|c|}{$\begin{array}{l}\text { Bourgeois } 1998(a) 3 \\
\text { Bourgeois } 1998 \text { (b)2 }\end{array}$}} & 40 & 8 & 44 & & - & $0.36(0.09,1.49)$ & 3.36 \\
\hline & & 43 & 8 & 44 & & & $0.22(0.04,1.10)$ & 2.64 \\
\hline Kahan 2009 & 203 & 309 & 206 & 313 & & & $0.99(0.71,1.39)$ & 16.67 \\
\hline Mathieu 2002 & 2 & 150 & 0 & 150 & & & $5.07(0.24,106.45)$ & 0.81 \\
\hline Michel 2005 & 113 & 150 & 103 & 150 & & $\rightarrow$ & $1.39(0.84,2.31)$ & 12.69 \\
\hline Wildi 2011 & 19 & 35 & 23 & 34 & $\rightarrow+$ & & $0.57(0.21,1.51)$ & 5.94 \\
\hline \multicolumn{5}{|c|}{ Subtotal $(I-$ squared $=46.7 \%, p=0.095)$} & & & $0.85(0.53,1.38)$ & 42.12 \\
\hline \multicolumn{5}{|c|}{ Overall $(\mathrm{l}$-squared $=44.6 \%, p=0.041)$} & से & & $0.78(0.59,1.03)$ & 100.00 \\
\hline \multicolumn{9}{|c|}{ NOTE: Weights are from random effects analysis } \\
\hline \multicolumn{9}{|c|}{ 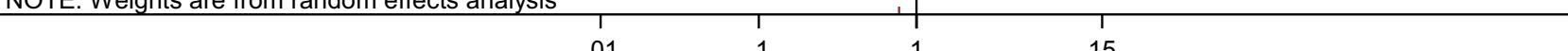 } \\
\hline
\end{tabular}

Fig. 5 Forest plot displaying the results of the meta-analyses comparing total adverse events with chondroitin sulfate versus placebo in patients with osteoarthritis: overall analysis and analyses of studies

\section{Discussion}

In our analysis, we found no statistically significant increase in odds between either GS, CS, or ASU, each compared with placebo, for any of the SOC-related disorders investigated, including gastrointestinal, cardiac, vascular, nervous system, skin and subcutaneous tissue, MSCT, and disorders of the renal and urinary systems. In addition, we found no statistically significant difference in odds between either GS, CS, or ASU treatment and placebo for severe and serious AEs or for withdrawals due to AEs. Almost all of this new evidence was predominantly associated with "high" certainty; "moderate" certainty of evidence was found with two outcomes overall (only with GS) and with a few other outcomes with or without concomitant anti-OA medication (mainly with GS and diacerein) because of imprecision (wide CIs around the estimates).

Overall, this meta-analysis found no statistically significant increase in odds for total AEs reported with GS (with or without concomitant anti-OA -medication) versus placebo, and we found reduced odds for total AEs with CS compared with placebo, particularly in studies in which no concomitant OA medications were permitted. These findings agree with those of previous meta-analyses that have demonstrated GS and CS to be as safe as placebo, with no with and without concomitant anti-osteoarthritis medication allowed. $C I$ confidence interval, $O A$ osteoarthritis

significant increase in odds for total AEs or dropouts due to AEs [6, 7, 21]. In a network meta-analysis, Zeng et al. [98] found no statistically significant increase in odds of specific AEs between GS and CS, each compared with placebo. The specific AEs investigated in that study were gastrointestinal, cardiovascular, central nervous system, infection, musculoskeletal and skin AEs.

A reduced odds of reporting renal and urinary disorders was found with CS compared with placebo in all the groups of studies analyzed, which was statistically significant overall (OR $0.40 ; 95 \%$ CI $0.22-0.74$ ) and in studies with concomitant anti-OA medications (OR 0.43; $95 \% \mathrm{CI}$ 0.23-0.81) (ESM-2). Likewise, as previously stated, the rate of total AEs was lower with CS than with placebo, and the difference in odds was statistically significant with studies with no concomitant anti-OA medication (OR 0.70; 95\% CI 0.51-0.98). However, the data available from the studies included in these analyses did not allow us to identify the specific events reported more frequently in patients receiving placebo, particularly in the Kahan et al. [72] study in which renal and urinary disorders were significantly more frequent in the placebo group (26 of 313 patients) compared with the CS group (9 of 309 patients). If these results are not due to chance, whether CS has potential for a protective effect against renal and urinary disorders deserves further 


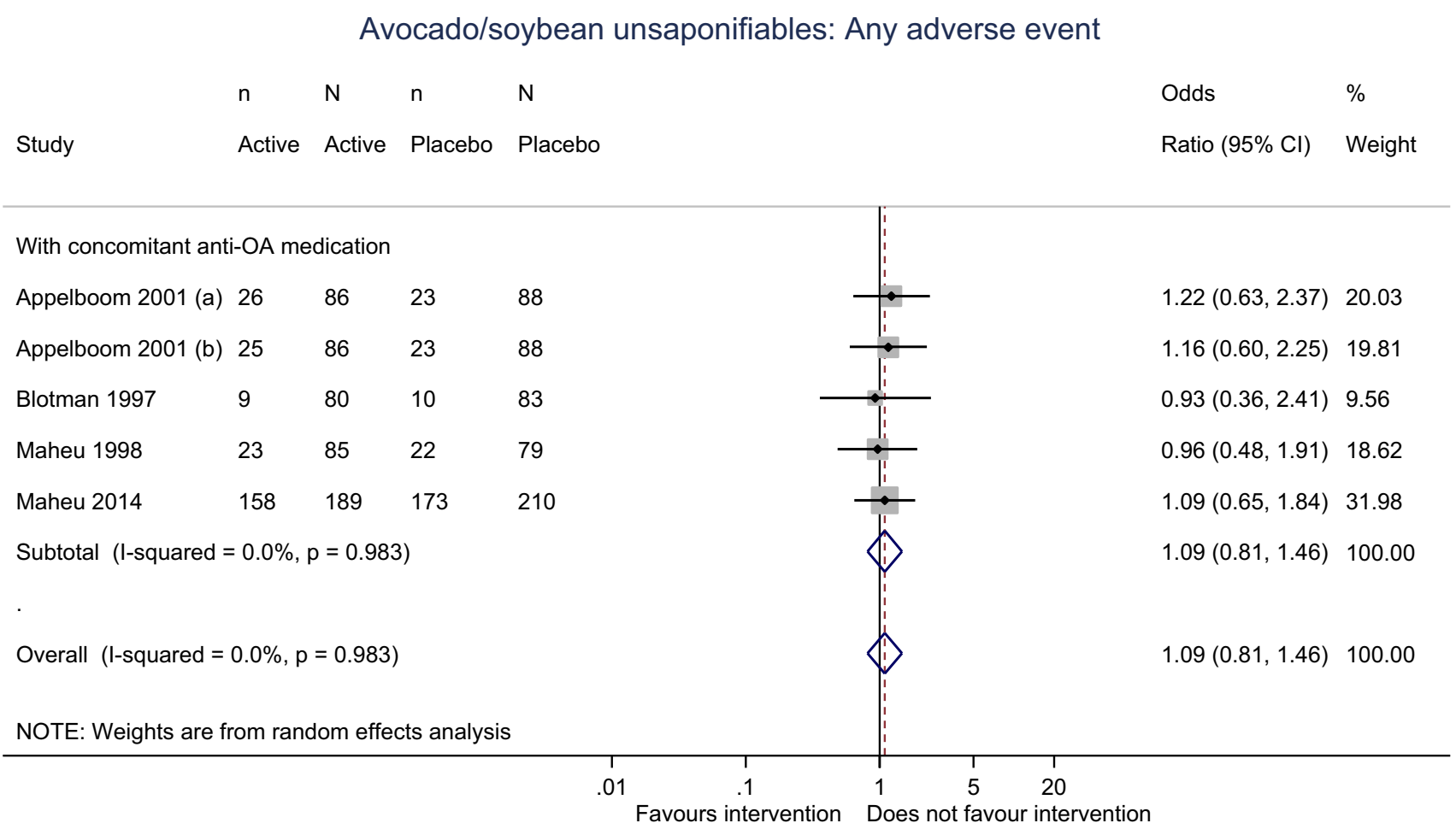

Fig. 6 Forest plot displaying the result of the meta-analysis comparing total adverse events with avocado soybean unsaponifiables versus placebo in patients with osteoarthritis: analysis of studies with con- comitant anti-osteoarthritis medications allowed. $C I$ confidence interval, $O A$ osteoarthritis

the studies included through our systematic review process used the pharmaceutical-grade proprietary ASU product Piascledine $^{\circledR}$ (Expanscience) (Table 2). Therefore, our findings regarding the safety profile of ASU may not apply to other preparations of ASU.

In a post-marketing safety analysis using data provided by the French spontaneous reporting system via the network of national pharmacovigilance centers, AEs affecting the skin, liver, gastrointestinal tract, and platelet aggregation (some being serious) have been reported with ASU [101]. This raises concerns about the safety of ASU supplements, particularly in real life, and requires further investigation.

In our safety analysis, the odds of any $\mathrm{AE}$ with diacerein were significantly higher than with placebo, with or without concomitant OA treatment (OR 2.22; 95\% CI 1.58-3.13). This was largely due to the increased odds of gastrointestinal AEs with diacerein versus placebo (OR 2.85; 95\% CI 2.02-4.04), diarrhea, abdominal pain, soft stools, and colitis being frequently reported, and a considerable increase in the odds of renal and urinary disorders with diacerein (OR 3.42; 95\% CI 2.36-4.96), urine discoloration being the most reported effect. These results were found in both studies with and without concomitant OA medications and are in agreement with a Cochrane meta-analysis, which found an increased risk of AEs with diacerein versus placebo: 


\section{Diacerein: Gastrointestinal disorders}

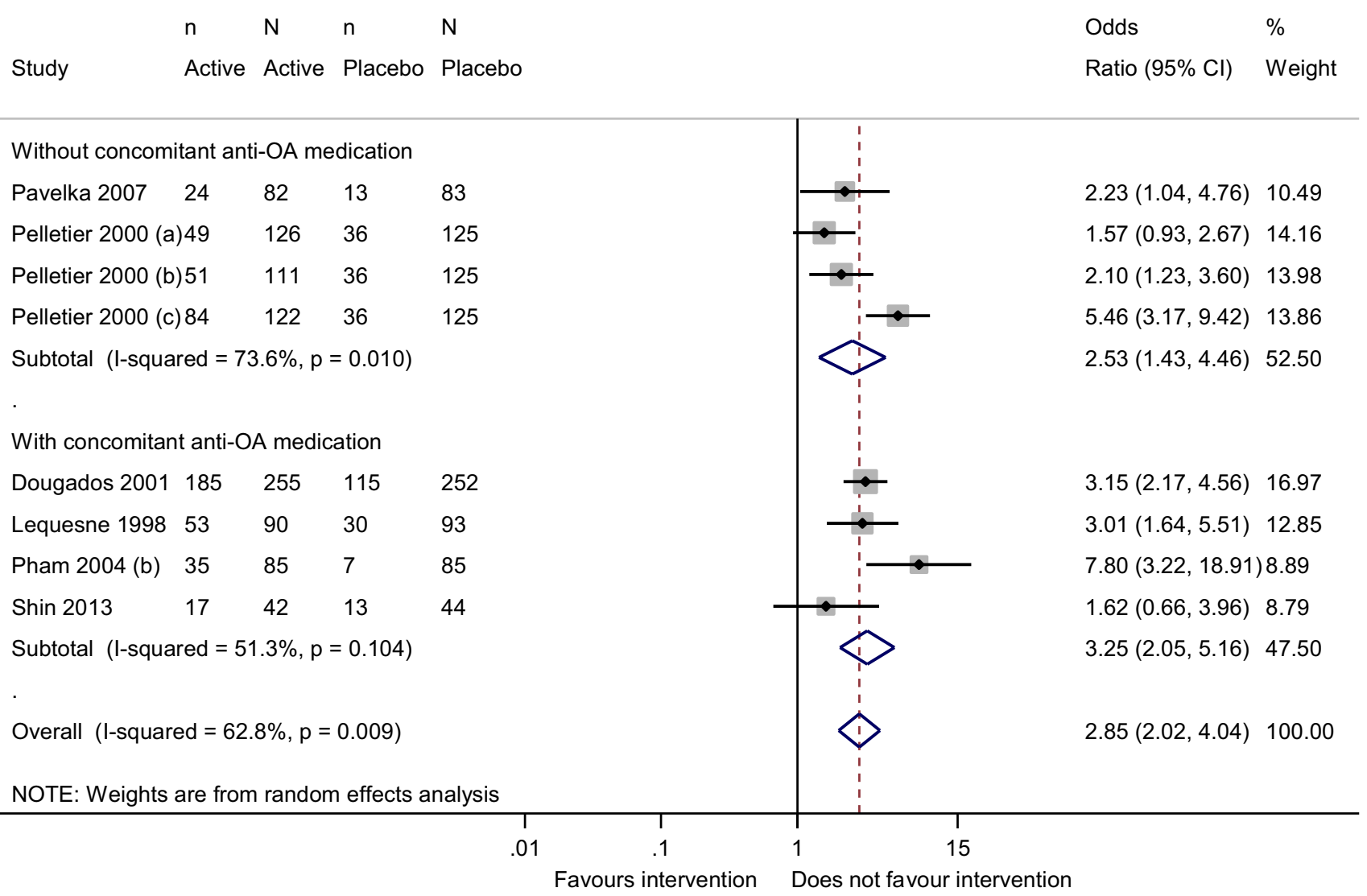

Fig. 7 Forest plot displaying the results of the meta-analyses comparing gastrointestinal disorders with diacerein versus placebo in patients with osteoarthritis: overall analysis and analyses of studies with and

diarrhea (RR 3.52; 95\% CI 2.42-5.11), urine discoloration (RR 13.01; 95\% CI 5.96-28.40), and rash or pruritus (RR 1.99; 95\% CI 0.94-4.23) [20]. In a meta-analysis of RCTs, Bartels et al. [5] also found a significantly increased risk of diarrhea with diacerein.

We also found significantly increased odds of dermatological disorders with diacerein versus placebo, overall (OR 2.18 ; 95\% CI 1.40-3.42), and specifically eczema, rash, pruritus, and urticaria; these odds significantly increased when concomitant anti-OA treatment was allowed (OR 2.47; 95\% CI 1.42-4.31) but not when there was no concomitant anti-OA medication (OR 1.74; 95\% CI 0.82-3.70). Oral NSAIDs were the rescue or concomitant anti-OA medications allowed during the trials for both the diacerein and the placebo groups (Table 2).

The odds of withdrawals due to AEs were significantly higher with diacerein than with placebo, overall (OR 1.85; $95 \%$ CI $\left.1.13-3.02 ; I^{2}=52.1 \%\right)$, and the increase was more important when concomitant anti-OA medications were allowed (OR 3.18; 95\% CI 1.85-5.47; $I^{2}=13.4 \%$ ), but no without concomitant anti-osteoarthritis medication allowed. $C I$ confidence interval, $O A$ osteoarthritis

significant increase was found without concomitant anti-OA medications (OR $1.22 ; 95 \%$ CI $0.80-1.87 ; I^{2}=0.0 \%$ ). As shown by these results, there is moderate but statistically significant heterogeneity with the overall analysis $\left(I^{2}=52.1 \%\right.$, $p=0.04)$, which was eliminated when the studies with $\left(I^{2}=13.4 \%, p=0.33\right)$ or without $\left(I^{2}=0.0 \%\right)$ concomitant anti-OA medications were considered separately. These results could suggest that the use of oral NSAIDs as rescue or concomitant medication might have played a role in the significantly increased number of withdrawals observed in patients receiving diacerein compared with those receiving placebo. However, we could not clinically explain this, as no drug interaction concern has been described with the coadministration of diacerein and NSAIDs [102]. This warrants further investigation given that similar results have been obtained regarding skin and subcutaneous tissue disorders, with eczema, rash, pruritus, and urticaria being the most reported specific events.

Whatever the group of studies considered (overall, with or without concomitant anti-OA medications), there was 


\section{Diacerein: Nervous system disorders}

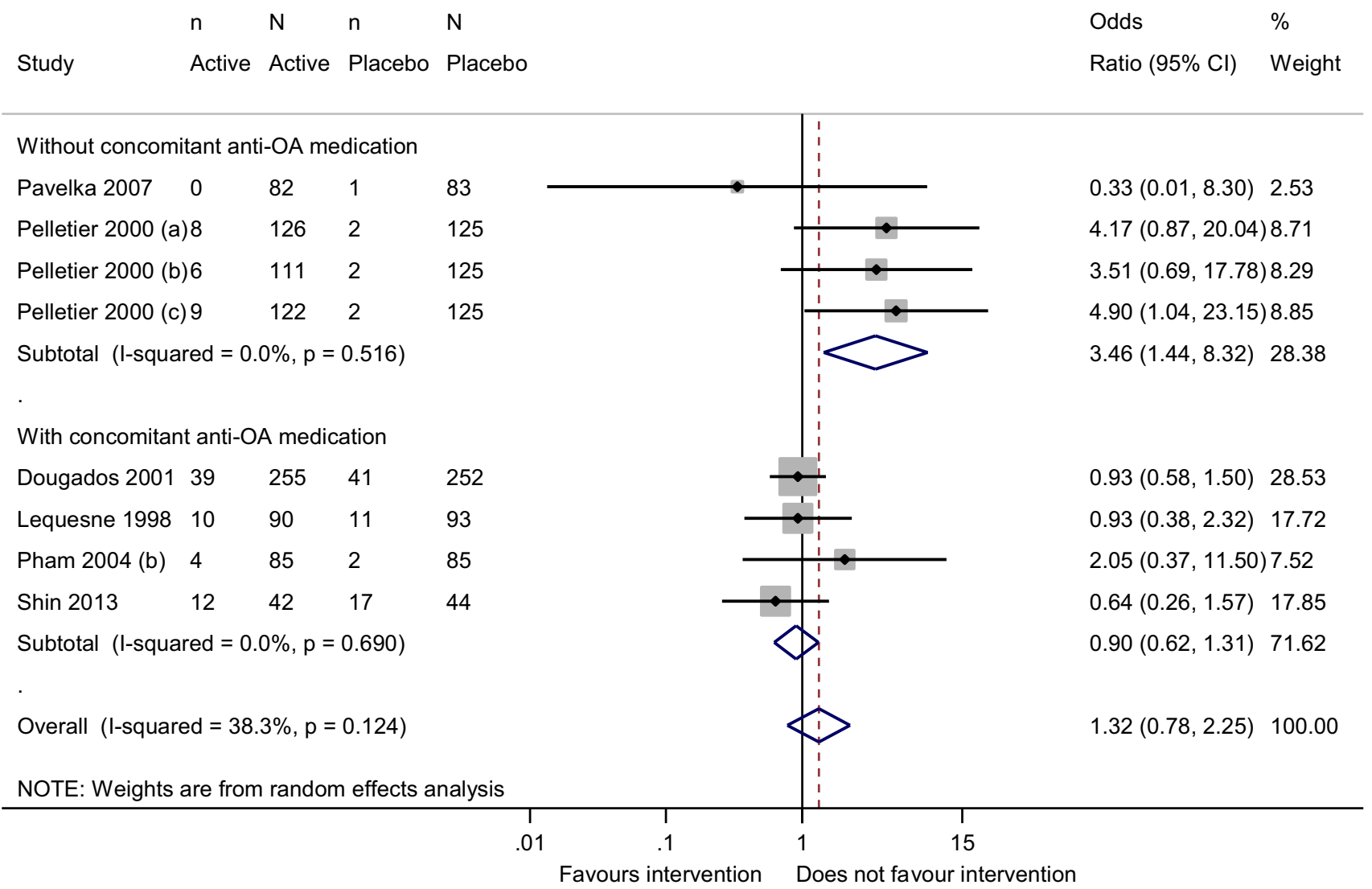

Fig. 8 Forest plot displaying the results of the meta-analyses comparing nervous system disorders with diacerein versus placebo in patients with osteoarthritis: overall analysis and analyses of studies

no increase in severe or serious AEs with diacerein versus placebo. Unlike previous meta-analyses on the safety of diacerein in the treatment of OA that used only the published data, we were able to use the full safety reports data for five of six studies analyzed (Tables 1 and 2), which makes our estimates more precise than these previous estimates.

The safety of diacerein was called into question following case reports of severe diarrhea and rare cases of serious hepatotoxicity; however, the reported cases of liver disorders involved patients aged $\geq 65$ years [103-105]. The European Medicines Agency (EMA) considered these safety issues and concluded that the benefit-risk balance of diacerein remained positive for hip and knee OA, particularly in patients aged $<65$ years [106]. It is advised that patients start treatment on half the normal dose (i.e., $50 \mathrm{mg}$ instead of $100 \mathrm{mg}$ daily) and stop taking diacerein if diarrhea occurs. The limited number of studies on diacerein in our meta-analysis meant we were unable to perform a dose-response effect analysis through subgroup analyses. However, the results of individual studies, as depicted by with and without concomitant anti-osteoarthritis medication allowed. $C I$ confidence interval, $O A$ osteoarthritis

Fig. 7, clearly indicated that gastrointestinal disorders were dose-dependent (detailed dose information in Tables 1 and 2). Indeed, for the five studies for which we used the full safety report data, the individual ORs for gastrointestinal disorders increased with the dose of diacerein (Fig. 7), from $50 \mathrm{mg}$ daily in the first arm (a) of the study by Pelletier et al. [52] to $100 \mathrm{mg}$ in the studies by Pavelka et al. [51], Dougados et al. [66], and Lequesne et al. [74] and $150 \mathrm{mg}$ in the third arm (c) of the study by Pelletier et al. [52]. This potential dose-response effect may explain the heterogeneity observed, whatever the group of studies considered (Fig. 7).

Unlike the adverse effects associated with diacerein, a recent RCT in patients with inadequately controlled type 2 diabetes mellitus (T2DM) showed that diacerein improved glycemic control; this led the authors to conclude that diacerein would be an adequate adjunct treatment option for patients with OA and T2DM [107]. Another recent RCT in patients with T2DM also concluded that diacerein could be 


\section{Diacerein: Skin and subcutaneous tissue disorders}

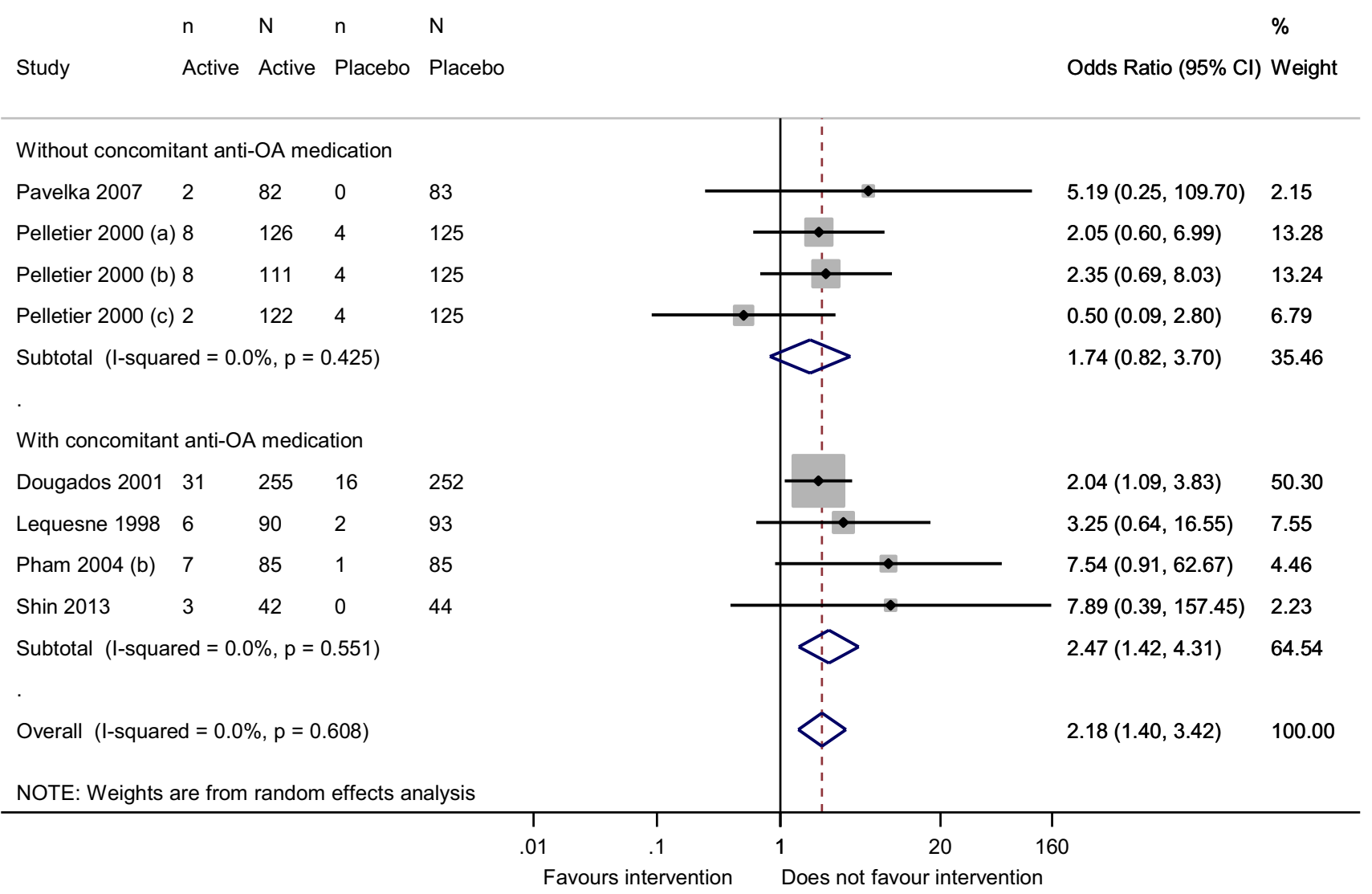

Fig. 9 Forest plot displaying the results of the meta-analyses comparing dermatological adverse events with diacerein versus placebo in patients with osteoarthritis: overall analysis and analyses of studies

a good treatment option in patients with T2DM with chronic kidney disease [108].

Given the warnings about adverse liver reactions, the current status or history of liver disease should be considered when prescribing diacerein. However, further investigation regarding the adverse liver effects of diacerein in patients with OA is warranted. In fact, a very recent study in rats with induced abnormal liver function concluded that rhein (the metabolite of diacerein) had a hepatoprotective effect, suggesting its possible concomitant use in patients receiving methotrexate, a treatment associated with kidney and liver function abnormalities [109].

Given the adverse effects associated with the use of diacerein, as shown by our analyses, and its positive effect on glycemic control, as reported by other studies, the usefulness of this compound in patients with OA should be assessed for each patient according to their individual characteristics, provided that its real benefit in terms of efficacy is proven. with and without concomitant anti-osteoarthritis medication allowed. $C I$ confidence interval, $O A$ osteoarthritis

\subsection{Strengths}

Our study has some specific strengths. First, we included only RCTs versus placebo, so the real effect was not underestimated. Second, we investigated many SOCs, not only "total AEs," "serious AEs," or "gastrointestinal AEs," as reported in many previous meta-analyses. Third, to avoid double counting of AEs, for each SOC, we considered the number of patients who experienced at least once any related AE. For total AEs, we considered the number of patients who experienced at least once any AE during the study.

\subsection{Limitations}

Our study also had some limitations. Many of the identified studies that met the inclusion criteria did not provide 


\section{Diacerein: Renal and urinary disorders}

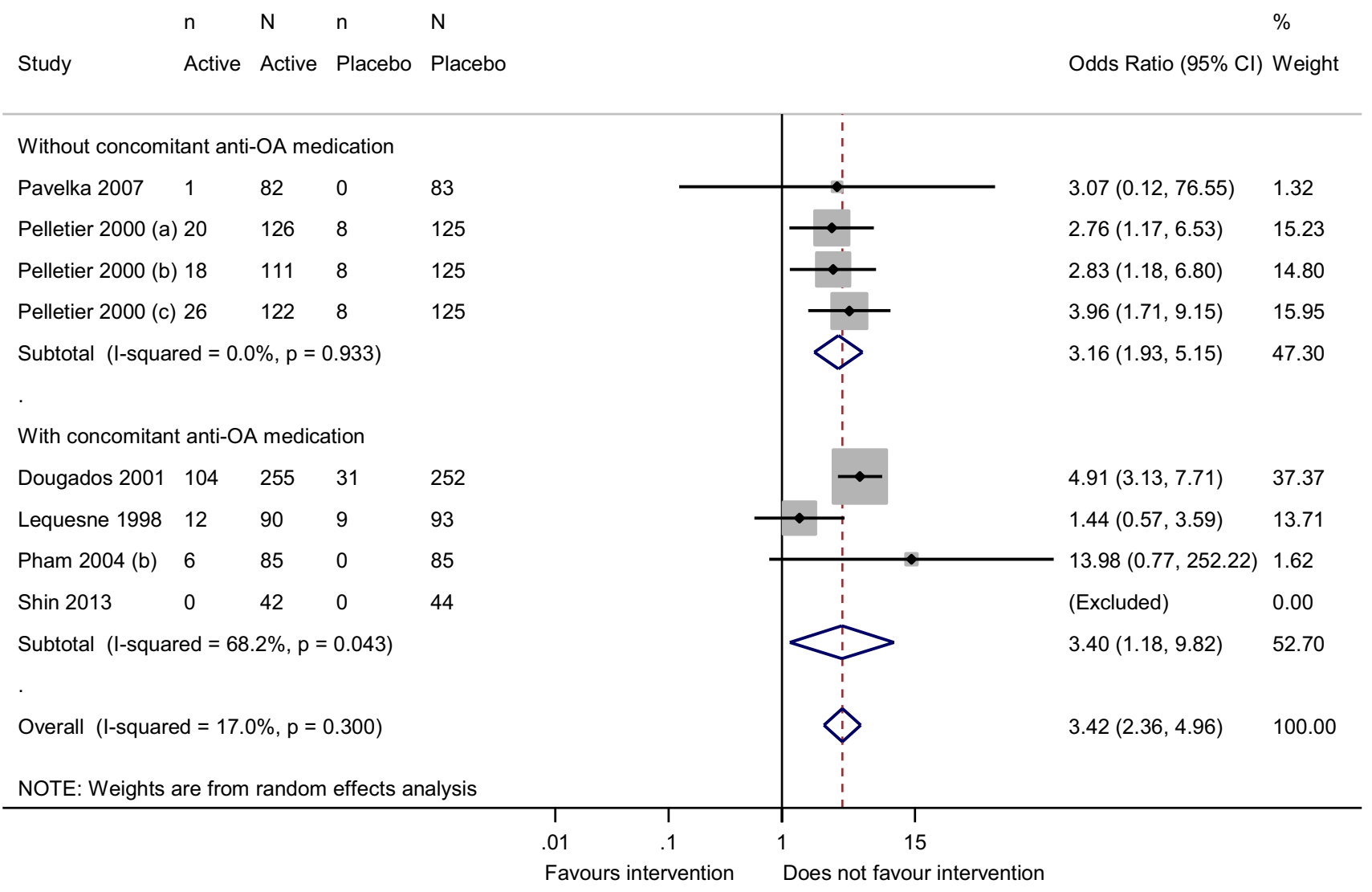

Fig. 10 Forest plot displaying the results of the meta-analyses comparing renal and urinary disorders with diacerein versus placebo in patients with osteoarthritis: overall analysis and analyses of studies with and without concomitant anti-osteoarthritis medication allowed. $C I$ confidence interval, $O A$ osteoarthritis

samples and including two or more comparisons. However, we decided not to apply this method, as we found that it only marginally and not significantly altered our results and did not modify our conclusions. Additionally, we wanted to obtain each comparison (active vs. placebo) with its real effect estimate and $95 \% \mathrm{CI}$ as if we chose to select only one pair of interventions.

\section{Conclusions}

The SYSADOAs GS and CS can be considered safe treatments for patients with OA. The harmlessness of ASU must be confirmed in future studies without concomitant anti-OA medication, but current evidence seems to support its safety. Our findings regarding ASU are based on the proprietary 


\section{Diacerein: Any adverse event}

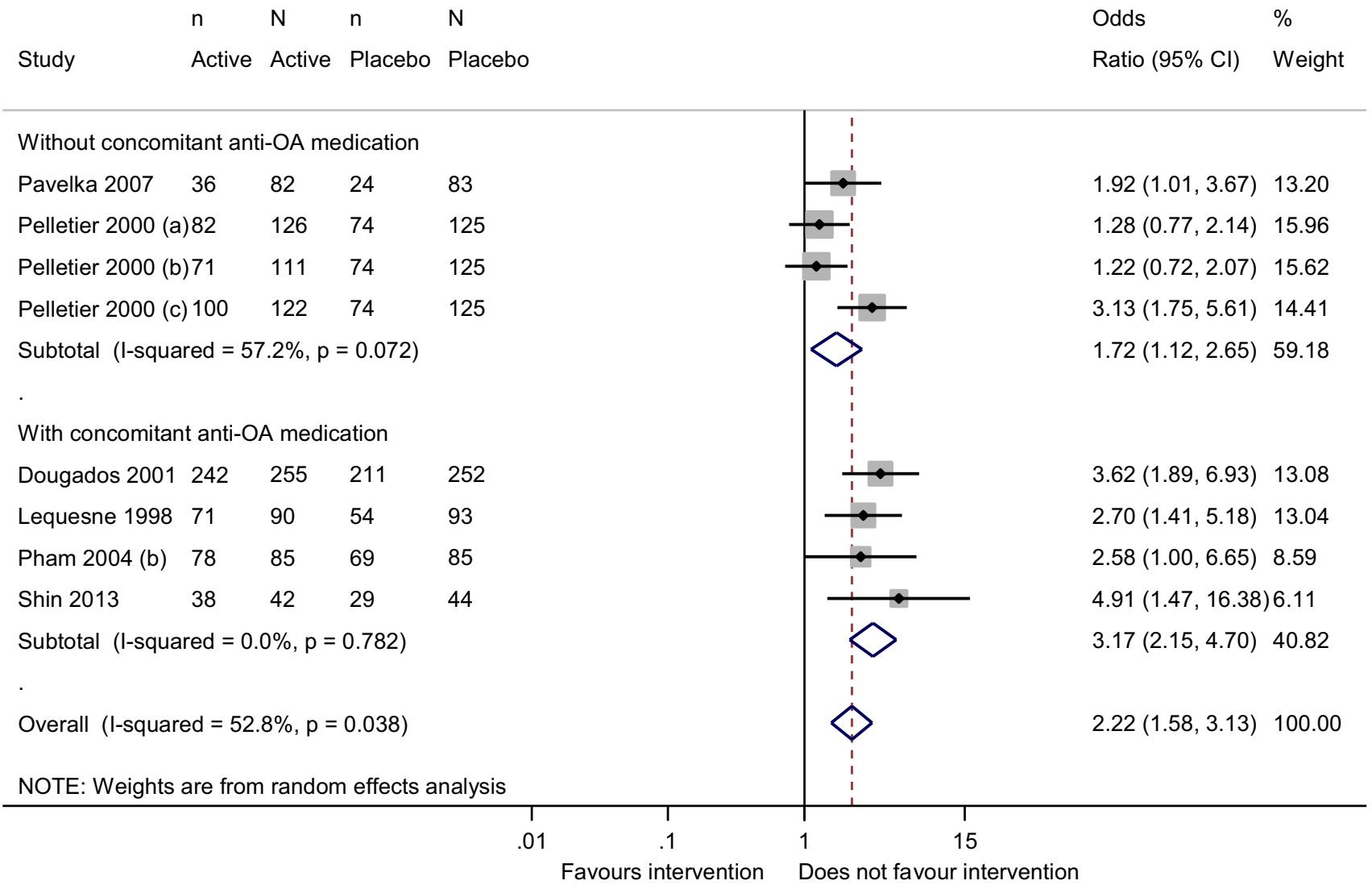

Fig. 11 Forest plot displaying the results of the meta-analyses comparing total adverse events with diacerein versus placebo in patients with osteoarthritis: overall analysis and analyses of studies with and without concomitant anti-osteoarthritis medication allowed. $C I$ confidence interval, $O A$ osteoarthritis

patient characteristics. This is in accordance with the EMA recommendations. The safety profile for coadministration of diacerein and oral NSAIDs requires further investigation. Finally, these results, which are based on data from RCTs, must be confirmed with pharmacovigilance data. 


\section{Diacerein: Withdrawals due to adverse events}

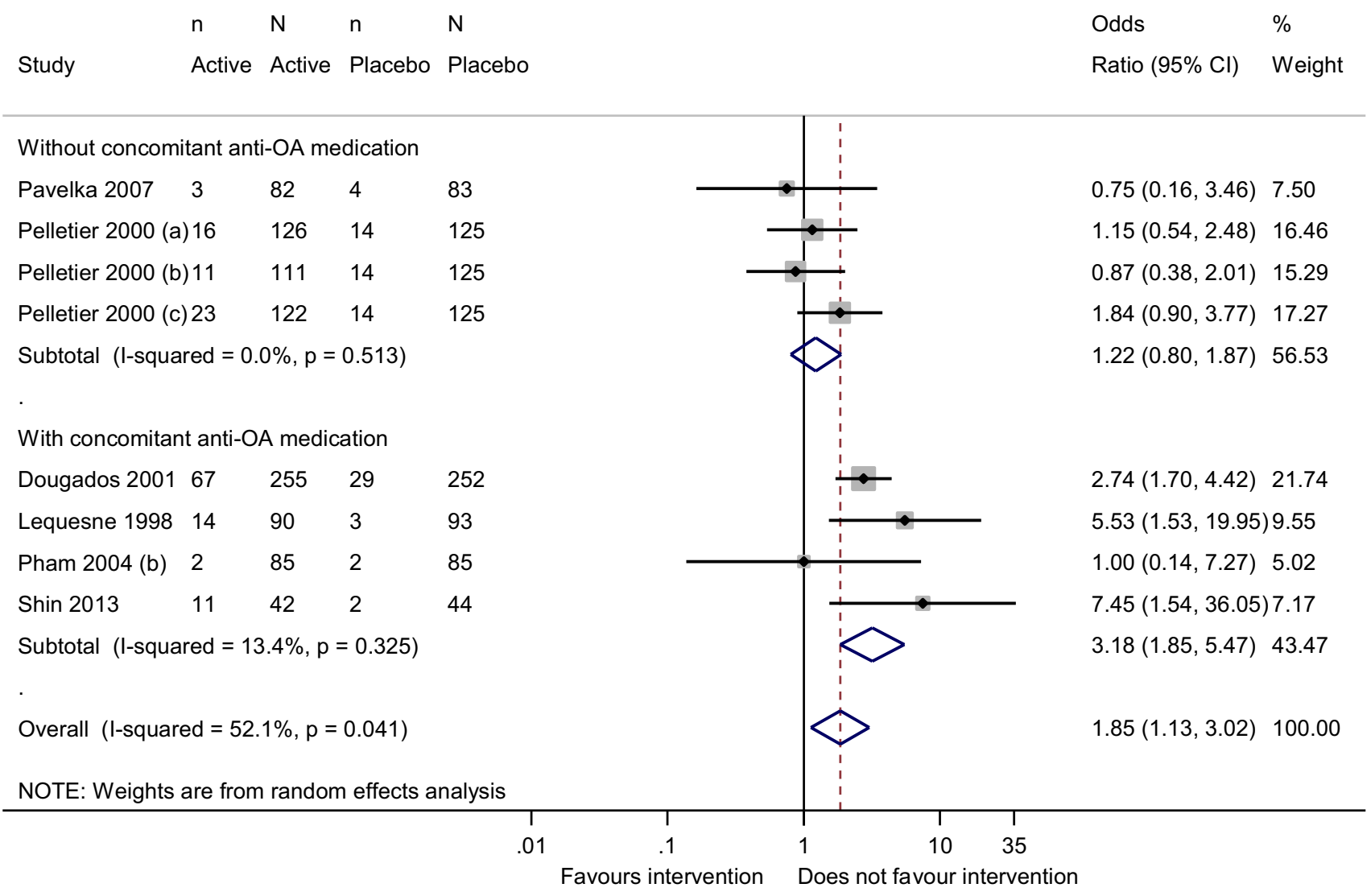

Fig. 12 Forest plot displaying the results of the meta-analyses comparing withdrawals due to adverse events with diacerein versus placebo in patients with osteoarthritis: overall analysis and analyses of

Acknowledgements This paper was written on behalf of the ESCEO Working Group on the safety of anti-osteoarthritis medications: Nasser Al-Daghri, Nigel Arden, Bernard Avouac, Olivier Bruyère, Roland Chapurlat, Philip Conaghan, Cyrus Cooper, Elizabeth Curtis, Elaine Dennison, Nicholas Fuggle, Gabriel Herrero-Beaumont, Germain Honvo, Margreet Kloppenburg, Stefania Maggi, Tim McAlindon, Alberto Migliore, Ouafa Mkinsi, François Rannou, Jean-Yves Reginster, René Rizzoli, Roland Roth, Thierry Thomas, Daniel Uebelhart, and Nicola Veronese. The authors of this paper are grateful to the authors of the articles included in the meta-analysis and to the pharmaceutical companies who kindly agreed to collaborate with this project by sharing the raw safety data from these studies. We express our sincere gratitude to IBSA Institut Biochimique SA (Switzerland), Laboratoires Genevrier (France), TRB Chemedica (Switzerland), and Expanscience (France). We thank Doctors Birgitta Johansson Cahlin, Hamed Esfandiari, Douglas S. Kalman, Lucio Rovati, Jean-Pierre Pelletier, Gabriel Herrero-Beaumont, Jolanda Cibere, Marlene Fransen, Antonella Fioravanti, Rianne Rozendaal, Joy Frestedt, Klaus Flechsenhar, Timothy McAlindon, Kichul Shin, and Yasuaki Nakagawa. We also thank Doctors Marta Bignamini (from IBSA), Véronique Leblanc studies with and without concomitant anti-osteoarthritis medication allowed. $C I$ confidence interval, $O A$ osteoarthritis

and Florence Masson (both from Expanscience), Cécile Clerc (from Genevrier), and My-Lam Eicher (from TRB), as well as Misters Patrice Paiement and Arturo Lanzarotti (IBSA) for their priceless help in sharing full safety data. We acknowledge the assistance and advice of Nancy Durieux and Frédéric de Lemos Esteves from the Library of Life Sciences, University of Liège, Belgium, in the preparation of the search strategies for the systematic review. We thank them very sincerely for their contribution to one of the most important parts of this research. The authors would like to express their most sincere gratitude to $\mathrm{Dr}$ Lisa Buttle, PhD, of Medscript Ltd., for her invaluable assistance with the manuscript preparation. Dr Lisa Buttle was entirely funded by the ESCEO asbl, Belgium.

\section{Compliance with Ethical Standards}

All authors meet the ICMJE criteria for authorship for this manuscript, take responsibility for the integrity of the work as a whole, and have given final approval to the version to be published. 
(A) Glucosamine sulfate

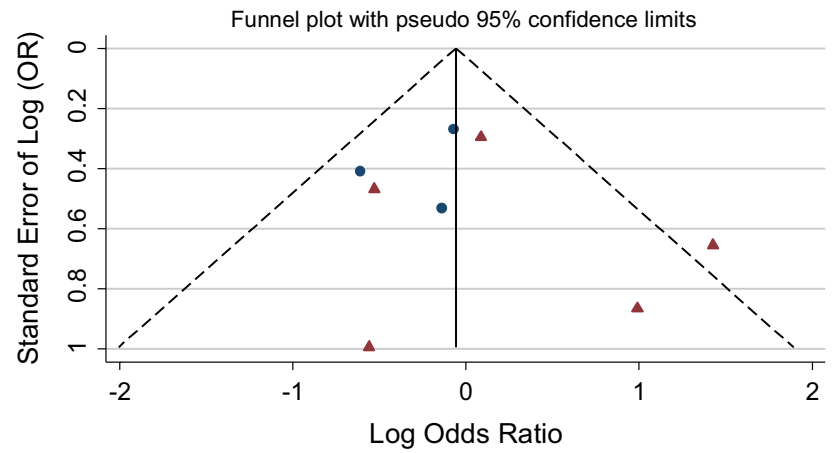

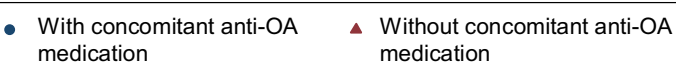

Glucosamine sulfate: Any adverse event

(B) Chondroitin sulfate

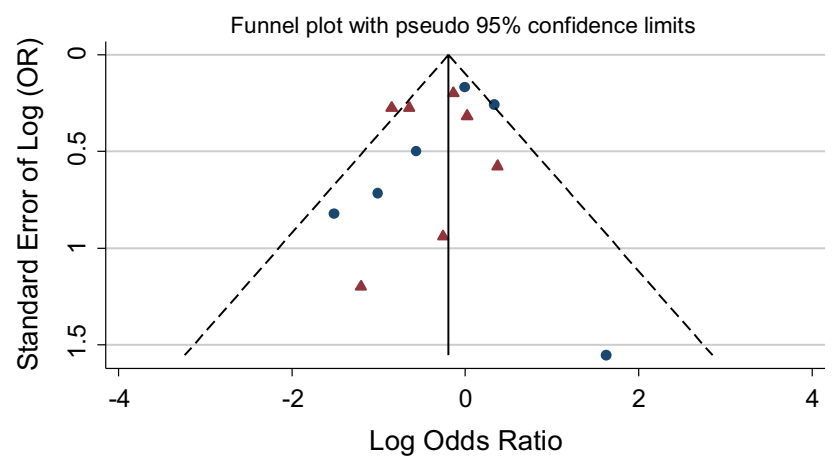

\begin{tabular}{ll}
\hline - With concomitant anti-OA \\
medication
\end{tabular}

Chondroitin sulfate: Any adverse event

Harbord's test: $p=0.54$

Fig. 13 Assessment of publication bias: funnel plots using data for the meta-analyses comparing total adverse events with a glucosamine sulfate, $\mathbf{b}$ chondroitin sulfate (Harbord's test: $p=0.54$ ), $\mathbf{c}$ diacerein,

Funding G Honvo was funded by the ESCEO, a Belgian not-for-profit organization. The ESCEO Working Group was entirely funded by the ESCEO. The ESCEO receives unrestricted educational grants, to support its educational and scientific activities, from non-governmental organizations, not-for-profit organizations, non-commercial and corporate partners. The choice of topics, participants, content, and agenda of the working groups as well as the writing, editing, submission, and reviewing of the manuscript are under the sole responsibility of the ESCEO without any influence from third parties.

Conflicts of interest $\mathrm{O}$ Bruyère has received grants from Biophytis, IBSA, MEDA, Servier, SMB, and Theramex, outside the submitted
(C) Diacerein

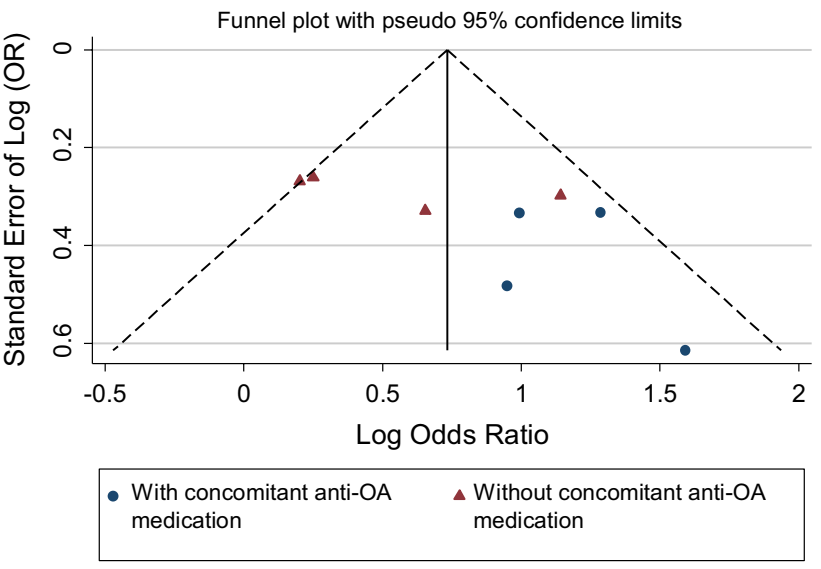

Diacerein: Any adverse event

(D) Avocado/soybean unsaponifiables

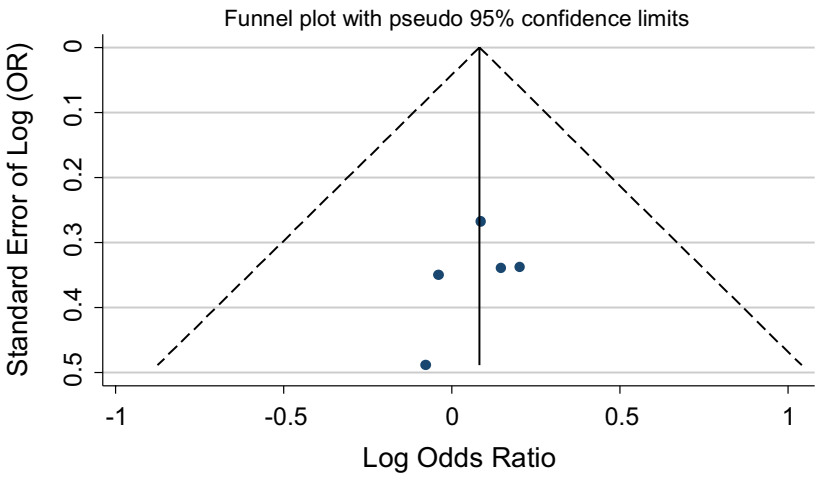

- With concomitant anti-OA medication

Avocado/soybean unsaponifiables: Any adverse event

and d avocado/soybean unsaponifiables, each versus placebo, in patients with osteoarthritis. $O A$ osteoarthritis, $O R$ odds ratio

work. C. Cooper has received personal fees from Alliance for Better Bone Health, Amgen, Eli Lilly, GlaxoSmithKline, Medtronic, Merck, Novartis, Pfizer, Roche, Servier, Takeda, and UCB, outside of the submitted work. J-Y. Reginster has received grants from IBSA-Genevrier, Mylan, CNIEL, and Radius Health (through their institution); consulting fees from IBSA-Genevrier, Mylan, CNIEL, Radius Health, and Pierre Fabre; fees for participation in review activities from IBSAGenevrier, MYLAN, CNIEL, Radius Health, and Teva; payment for lectures from AgNovos, CERIN, CNIEL, Dairy Research Council (DRC), Echolight, IBSA-Genevrier, Mylan, Pfizer Consumer Health, Teva, and Theramex, outside of the submitted work. B. Avouac has received consulting fees from Novartis, BMS, Roche, Janssen Cilag, Expanscience, and IRIS and fees for participating in research activities 
Table 3 Summary of findings for glucosamine sulfate vs. placebo in patients with osteoarthritis

\begin{tabular}{|c|c|c|c|c|c|}
\hline \multirow[t]{2}{*}{ Outcomes } & \multirow{2}{*}{$\begin{array}{l}\text { No. of participants } \\
\text { (studies), follow-up }\end{array}$} & \multirow{2}{*}{$\begin{array}{l}\text { Certainty of } \\
\text { the evidence } \\
\text { (GRADE) }\end{array}$} & \multirow{2}{*}{$\begin{array}{l}\text { Overall relative effect } \\
(95 \% \mathrm{CI})\end{array}$} & \multicolumn{2}{|c|}{ Anticipated absolute effects } \\
\hline & & & & Risk with placebo & $\begin{array}{l}\text { Risk difference with } \\
\text { glucosamine sulfate }\end{array}$ \\
\hline Gastrointestinal AEs & 1351 (9 RCTs) & $\begin{array}{l}\oplus \oplus \oplus \oplus \\
\text { High }\end{array}$ & OR $1.02(0.74-1.40)$ & 150 per 1000 & $\begin{array}{l}3 \text { more per } 1000 \\
\text { ( } 34 \text { fewer to } 48 \text { more) }\end{array}$ \\
\hline $\begin{array}{l}\text { Skin and subcutaneous tissue } \\
\text { disorders }\end{array}$ & 1351 (9 RCTs) & $\begin{array}{l}\oplus \oplus \oplus \oplus \\
\text { High }\end{array}$ & OR $0.80(0.43-1.48)$ & 39 per 1000 & $\begin{array}{l}7 \text { fewer per } 1000 \\
\text { (22 fewer to } 17 \text { more) }\end{array}$ \\
\hline Renal and urinary disorders & 1149 (8 RCTs) & $\begin{array}{l}\oplus \oplus \oplus \oplus \\
\text { High }\end{array}$ & Not estimable & 0 per 1000 & $\begin{array}{l}0 \text { fewer per } 1000 \\
(0 \text { fewer to } 0 \text { fewer })\end{array}$ \\
\hline Severe AEs & 1351 (9 RCTs) & $\begin{array}{l}\oplus \oplus \oplus \bigcirc \\
\text { Moderate }^{\mathrm{a}}\end{array}$ & OR $1.46(0.26-8.13)$ & 12 per 1000 & $\begin{array}{l}5 \text { more per } 1000 \\
\text { ( } 9 \text { fewer to } 77 \text { more) }\end{array}$ \\
\hline Serious AEs & 1351 (9 RCTs) & $\begin{array}{l}\oplus \oplus \oplus \bigcirc \\
\text { Moderate }^{\mathrm{a}}\end{array}$ & OR $2.04(0.37-11.36)$ & 3 per 1000 & $\begin{array}{l}3 \text { more per } 1000 \\
\text { ( } 2 \text { fewer to } 30 \text { more) }\end{array}$ \\
\hline Withdrawals due to AEs & 1351 (9 RCTs) & $\begin{array}{l}\oplus \oplus \oplus \oplus \\
\text { High }\end{array}$ & OR $0.86(0.51-1.42)$ & 52 per 1000 & $\begin{array}{l}7 \text { fewer per } 1000 \\
\text { ( } 25 \text { fewer to } 20 \text { more) }\end{array}$ \\
\hline
\end{tabular}

GRADE Working Group grades of evidence: High certainty we are very confident that the true effect lies close to that of the estimate of the effect; Moderate certainty we are moderately confident in the effect estimate: the true effect is likely to be close to the estimate of the effect, but there is a possibility that it is substantially different; Low certainty our confidence in the effect estimate is limited: the true effect may be substantially different from the estimate of the effect: Very low certainty we have very little confidence in the effect estimate: the true effect is likely to be substantially different from the estimate of effect

The risk in the intervention group (and its $95 \% \mathrm{CI}$ ) is based on the assumed risk in the comparison group and the relative effect of the intervention (and its $95 \% \mathrm{CI}$ )

$A E$ adverse event, $C I$ confidence interval, $O R$ odds ratio, $R C T$ randomised controlled trial

${ }^{a}$ Wide confidence interval because of low number of events

Table 4 Summary of findings for chondroitin sulfate vs. placebo in patients with osteoarthritis

\begin{tabular}{|c|c|c|c|c|c|}
\hline \multirow[t]{2}{*}{ Outcomes } & \multirow{2}{*}{$\begin{array}{l}\text { No. of participants } \\
\text { (studies), follow-up }\end{array}$} & \multirow{2}{*}{$\begin{array}{l}\text { Certainty of } \\
\text { the evidence } \\
\text { (GRADE) }\end{array}$} & \multirow{2}{*}{$\begin{array}{l}\text { Overall relative effect } \\
(95 \% \mathrm{CI})\end{array}$} & \multicolumn{2}{|c|}{ Anticipated absolute effects } \\
\hline & & & & Risk with placebo & $\begin{array}{l}\text { Risk difference with } \\
\text { chondroitin sulfate }\end{array}$ \\
\hline Gastrointestinal AEs & 2877 (12 RCTs) & $\begin{array}{l}\oplus \oplus \oplus \oplus \\
\text { High }\end{array}$ & OR 0.77 (0.59-1.00) & 159 per 1000 & $\begin{array}{l}32 \text { fewer per } 1000 \\
\text { (58 fewer to } 0 \text { fewer) }\end{array}$ \\
\hline $\begin{array}{l}\text { Skin and subcutaneous tissue } \\
\text { disorders }\end{array}$ & 2877 (12 RCTs) & $\begin{array}{l}\oplus \oplus \oplus \oplus \\
\text { High }\end{array}$ & OR $1.07(0.62-1.84)$ & 31 per 1000 & $\begin{array}{l}2 \text { more per } 1000 \\
\text { (11 fewer to } 24 \text { more) }\end{array}$ \\
\hline Renal and urinary disorders & 2877 (12 RCTs) & $\begin{array}{l}\oplus \oplus \oplus \oplus \\
\text { High }\end{array}$ & OR $0.40(0.22-0.74)$ & 26 per 1000 & $\begin{array}{l}15 \text { fewer per } 1000 \\
\text { (20 fewer to } 7 \text { fewer) }\end{array}$ \\
\hline Severe AEs & 2877 (12 RCTs) & $\begin{array}{l}\oplus \oplus \oplus \oplus \\
\text { High }\end{array}$ & OR $0.82(0.47-1.45)$ & 86 per 1000 & $\begin{array}{l}14 \text { fewer per } 1000 \\
\text { (44 fewer to } 34 \text { more) }\end{array}$ \\
\hline Serious AEs & 2877 (12 RCTs) & $\begin{array}{l}\oplus \oplus \oplus \oplus \\
\text { High }\end{array}$ & OR $1.13(0.84-1.52)$ & 75 per 1000 & $\begin{array}{l}9 \text { more per } 1000 \\
\text { (11 fewer to } 35 \text { more) }\end{array}$ \\
\hline Withdrawals due to AEs & 2877 (12 RCTs) & $\begin{array}{l}\oplus \oplus \oplus \oplus \\
\text { High }\end{array}$ & OR $0.72(0.44-1.16)$ & 56 per 1000 & $\begin{array}{l}15 \text { fewer per } 1000 \\
\text { (31 fewer to } 8 \text { more) }\end{array}$ \\
\hline
\end{tabular}

GRADE Working Group grades of evidence: High certainty we are very confident that the true effect lies close to that of the estimate of the effect; Moderate certainty we are moderately confident in the effect estimate: the true effect is likely to be close to the estimate of the effect, but there is a possibility that it is substantially different; Low certainty our confidence in the effect estimate is limited: the true effect may be substantially different from the estimate of the effect: Very low certainty we have very little confidence in the effect estimate: the true effect is likely to be substantially different from the estimate of effect

The risk in the intervention group (and its $95 \% \mathrm{CI}$ ) is based on the assumed risk in the comparison group and the relative effect of the intervention (and its $95 \% \mathrm{CI}$ )

$A E$ adverse event, $C I$ confidence interval, $O R$ odds ratio, $R C T$ randomised controlled trial 
Table 5 Summary of findings for diacerein vs. placebo in patients with osteoarthritis

\begin{tabular}{|c|c|c|c|c|c|}
\hline \multirow[t]{2}{*}{ Outcomes } & \multirow{2}{*}{$\begin{array}{l}\text { No. of participants } \\
\text { (studies), follow-up }\end{array}$} & \multirow{2}{*}{$\begin{array}{l}\text { Certainty of the } \\
\text { evidence (GRADE) }\end{array}$} & \multirow{2}{*}{$\begin{array}{l}\text { Overall relative effect } \\
(95 \% \mathrm{CI})\end{array}$} & \multicolumn{2}{|c|}{ Anticipated absolute effects } \\
\hline & & & & Risk with placebo & $\begin{array}{l}\text { Risk difference with } \\
\text { diacerein }\end{array}$ \\
\hline Gastrointestinal AEs & 1595 (6 RCTs) & $\begin{array}{l}\oplus \oplus \oplus \oplus \\
\text { High }\end{array}$ & OR 2.85 (2.02-4.04) & 314 per 1000 & $\begin{array}{l}252 \text { more per } 1000 \\
\text { ( } 166 \text { more to } 335 \text { more) }\end{array}$ \\
\hline $\begin{array}{l}\text { Skin and subcutaneous tis- } \\
\text { sue disorders }\end{array}$ & 1595 (6 RCTs) & $\begin{array}{l}\oplus \oplus \oplus \oplus \\
\text { High }\end{array}$ & OR $2.18(1.40-3.42)$ & 34 per 1000 & $\begin{array}{l}37 \text { more per } 1000 \\
(13 \text { more to } 73 \text { more })\end{array}$ \\
\hline Renal and urinary disorders & 1595 (6 RCTs) & $\begin{array}{l}\oplus \oplus \oplus \oplus \\
\text { High }\end{array}$ & OR $3.42(2.36-4.96)$ & 70 per 1000 & $\begin{array}{l}135 \text { more per } 1000 \\
\text { ( } 81 \text { more to } 203 \text { more) }\end{array}$ \\
\hline Severe AEs & 1088 (5 RCTs) & $\begin{array}{l}\oplus \oplus \oplus \oplus \\
\text { High }\end{array}$ & OR $1.39(0.78-2.48)$ & 40 per 1000 & $\begin{array}{l}15 \text { more per } 1000 \\
(8 \text { fewer to } 53 \text { more })\end{array}$ \\
\hline Serious AEs & 1595 (6 RCTs) & $\begin{array}{l}\oplus \oplus \oplus \oplus \\
\text { High }\end{array}$ & OR 0.95 (0.68-1.33) & 128 per 1000 & $\begin{array}{l}6 \text { fewer per } 1000 \\
\text { (37 fewer to } 35 \text { more) }\end{array}$ \\
\hline Withdrawals due to AEs & 1595 (6 RCTs) & $\begin{array}{l}\oplus \oplus \oplus \oplus \\
\text { High }\end{array}$ & OR 1.85 (1.13-3.02) & 79 per 1000 & $\begin{array}{l}58 \text { more per } 1000 \\
(9 \text { more to } 127 \text { more })\end{array}$ \\
\hline
\end{tabular}

GRADE Working Group grades of evidence: High certainty we are very confident that the true effect lies close to that of the estimate of the effect; Moderate certainty we are moderately confident in the effect estimate: the true effect is likely to be close to the estimate of the effect, but there is a possibility that it is substantially different; Low certainty our confidence in the effect estimate is limited: the true effect may be substantially different from the estimate of the effect; Very low certainty we have very little confidence in the effect estimate: the true effect is likely to be substantially different from the estimate of effect

The risk in the intervention group (and its $95 \% \mathrm{CI}$ ) is based on the assumed risk in the comparison group and the relative effect of the intervention (and its $95 \% \mathrm{CI}$ )

$A E$ adverse event, $C I$ confidence interval, $O R$ odds ratio, $R C T$ randomised controlled trial

Table 6 Summary of findings for avocado/soybean unsaponifiables vs. placebo in patients with osteoarthritis

\begin{tabular}{|c|c|c|c|c|c|}
\hline \multirow[t]{2}{*}{ Outcomes } & \multirow{2}{*}{$\begin{array}{l}\text { No. of participants } \\
\text { (studies), follow-up }\end{array}$} & \multirow{2}{*}{$\begin{array}{l}\text { Certainty of evi- } \\
\text { dence (GRADE) }\end{array}$} & \multirow{2}{*}{$\begin{array}{l}\text { Relative effect } \\
(95 \% \mathrm{CI})\end{array}$} & \multicolumn{2}{|c|}{ Anticipated absolute effects } \\
\hline & & & & Risk with placebo & Risk difference with ASU \\
\hline Gastrointestinal AEs & 986 (4 RCTs) & $\begin{array}{l}\oplus \oplus \oplus \oplus \\
\text { High }\end{array}$ & $\begin{array}{l}\text { OR } 0.91 \\
\quad(0.65-1.27)\end{array}$ & 174 per 1000 & $\begin{array}{l}13 \text { fewer per } 1000 \\
\text { ( } 54 \text { fewer to } 37 \text { more) }\end{array}$ \\
\hline Skin and subcutaneous tissue disorders & 986 (4 RCTs) & $\begin{array}{l}\oplus \oplus \oplus \oplus \\
\text { High }\end{array}$ & $\begin{array}{l}\text { OR } 0.91 \\
\quad(0.26-3.14)\end{array}$ & 41 per 1000 & $\begin{array}{l}4 \text { fewer per } 1000 \\
\text { (30 fewer to } 78 \text { more) }\end{array}$ \\
\hline Renal and urinary disorders & 986 (4 RCTs) & $\begin{array}{l}\oplus \oplus \oplus \oplus \\
\text { High }\end{array}$ & $\begin{array}{l}\text { OR } 1.12 \\
(0.43-2.87)\end{array}$ & 20 per 1000 & $\begin{array}{l}2 \text { more per } 1000 \\
\text { (11 fewer to } 35 \text { more) }\end{array}$ \\
\hline Severe AEs & 986 (4 RCTs) & $\begin{array}{l}\oplus \oplus \oplus \oplus \\
\text { High }\end{array}$ & $\begin{array}{l}\text { OR } 0.89 \\
\quad(0.61-1.30)\end{array}$ & 157 per 1000 & $\begin{array}{l}15 \text { fewer per } 1000 \\
\text { (55 fewer to } 38 \text { more) }\end{array}$ \\
\hline Serious AEs & 986 (4 RCTs) & $\begin{array}{l}\oplus \oplus \oplus \oplus \\
\text { High }\end{array}$ & $\begin{array}{l}\text { OR } 1.31 \\
\quad(0.85-2.00)\end{array}$ & 120 per 1000 & $\begin{array}{l}31 \text { more per } 1000 \\
\text { (16 fewer to } 94 \text { more) }\end{array}$ \\
\hline Withdrawals due to AEs & 986 (4 RCTs) & $\begin{array}{l}\oplus \oplus \oplus \oplus \\
\text { High }\end{array}$ & $\begin{array}{l}\text { OR } 0.97 \\
(0.55-1.70)\end{array}$ & 48 per 1000 & $\begin{array}{l}1 \text { fewer per } 1000 \\
\text { ( } 21 \text { fewer to } 31 \text { more) }\end{array}$ \\
\hline
\end{tabular}

GRADE Working Group grades of evidence: Highcertainty we are very confident that the true effect lies close to that of the estimate of the effect; Moderate certainty we are moderately confident in the effect estimate: the true effect is likely to be close to the estimate of the effect, but there is a possibility that it is substantially different; Low certainty our confidence in the effect estimate is limited: the true effect may be substantially different from the estimate of the effect; Very low certainty we have very little confidence in the effect estimate: the true effect is likely to be substantially different from the estimate of effect

The risk in the intervention group (and its $95 \% \mathrm{CI}$ ) is based on the assumed risk in the comparison group and the relative effect of the intervention (and its $95 \% \mathrm{CI}$ )

$A E$ adverse event, $C I$ confidence interval, $O R$ odds ratio, $R C T$ randomised controlled trial

from Sanofi, Amgen, Takeda, Allegan, Abbvie, Vertex, AstraZeneca, Ipsen, Leadiant, Otsuka, Jazz, Leo, and alexion, outside of the submitted work. G. Honvo, R. Rizzoli, O. Mkinsi, A. Geerinck, A. Charles and V. Rabenda have no conflicts of interest that are directly relevant to the content of this article. 
Open Access This article is distributed under the terms of the Creative Commons Attribution-NonCommercial 4.0 International License (http://creativecommons.org/licenses/by-nc/4.0/), which permits any noncommercial use, distribution, and reproduction in any medium, provided you give appropriate credit to the original author(s) and the source, provide a link to the Creative Commons license, and indicate if changes were made.

\section{References}

1. Bijlsma JW, Berenbaum F, Lafeber FP. Osteoarthritis: an update with relevance for clinical practice. Lancet. 2011;377(9783):2115-26. https://doi.org/10.1016/S0140 $-6736(11) 60243-2$.

2. Pereira D, Peleteiro B, Araujo J, Branco J, Santos RA, Ramos E. The effect of osteoarthritis definition on prevalence and incidence estimates: a systematic review. Osteoarthritis Cartilage. 2011;19(11):1270-85. https://doi.org/10.1016/j. joca.2011.08.009.

3. Vos T, Flaxman AD, Naghavi M, Lozano R, Michaud C, Ezzati M, et al. Years lived with disability (YLDs) for 1160 sequelae of 289 diseases and injuries 1990-2010: a systematic analysis for the Global Burden of Disease Study 2010. Lancet. 2012;380(9859):2163-96. https://doi.org/10.1016/s0140 $-6736(12) 61729-2$.

4. Bruyere O, Cooper C, Pelletier JP, Branco J, Brandi ML, Guillemin $\mathrm{F}$, et al. An algorithm recommendation for the management of knee osteoarthritis in Europe and internationally: a report from a task force of the European Society for Clinical and Economic Aspects of Osteoporosis and Osteoarthritis (ESCEO). Semin Arthritis Rheum. 2014;44(3):253-63. https://doi.org/10.1016/j. semarthrit.2014.05.014.

5. Bartels EM, Bliddal H, Schondorff PK, Altman RD, Zhang W, Christensen R. Symptomatic efficacy and safety of diacerein in the treatment of osteoarthritis: a meta-analysis of randomized placebo-controlled trials. Osteoarthritis Cartilage. 2010;18(3):289-96. https://doi.org/10.1016/j.joca.2009.10.006.

6. Towheed TE, Maxwell L, Anastassiades TP, Shea B, Houpt J, Robinson V et al. Glucosamine therapy for treating osteoarthritis. Cochrane Database Syst Rev. 2009(2):CD002946. https://doi. org/10.1002/14651858.cd002946.pub2.

7. Singh JA, Noorbaloochi S, MacDonald R, Maxwell LJ. Chondroitin for osteoarthritis. Cochrane Database Syst Rev. 2015;1:CD005614. https://doi.org/10.1002/14651858.cd005614. pub2.

8. Reginster JY. The efficacy of glucosamine sulfate in osteoarthritis: financial and nonfinancial conflict of interest. Arthritis Rheum. 2007;56(7):2105-10. https://doi.org/10.1002/art.22852.

9. Eriksen P, Bartels EM, Altman RD, Bliddal H, Juhl C, Christensen R. Risk of bias and brand explain the observed inconsistency in trials on glucosamine for symptomatic relief of osteoarthritis: a meta-analysis of placebo-controlled trials. Arthritis Care Res (Hoboken). 2014;66(12):1844-55. https://doi.org/10.1002/ acr.22376.

10. Hochberg MC. Structure-modifying effects of chondroitin sulfate in knee osteoarthritis: an updated meta-analysis of randomized placebo-controlled trials of 2-year duration. Osteoarthritis Cartilage. 2010;18(Suppl 1):S28-31. https://doi.org/10.1016/j. joca.2010.02.016.

11. McAlindon TE, Bannuru RR, Sullivan MC, Arden NK, Berenbaum F, Bierma-Zeinstra SM, et al. OARSI guidelines for the non-surgical management of knee osteoarthritis. Osteoarthritis Cartilage. 2014;22(3):363-88. https://doi.org/10.1016/j. joca.2014.01.003.
12. Hochberg MC, Altman RD, April KT, Benkhalti M, Guyatt G, McGowan J, et al. American College of Rheumatology 2012 recommendations for the use of nonpharmacologic and pharmacologic therapies in osteoarthritis of the hand, hip, and knee. Arthritis Care Res. 2012;64(4):465-74. https://doi.org/10.1002/ acr.21596.

13. Jordan KM, Arden NK, Doherty M, Bannwarth B, Bijlsma JWJ, Dieppe P, et al. EULAR Recommendations 2003: an evidence based approach to the management of knee osteoarthritis: Report of a Task Force of the Standing Committee for International Clinical Studies Including Therapeutic Trials (ESCISIT). Ann Rheum Dis. 2003;62(12):1145-55. https://doi.org/10.1136/ ard.2003.011742.

14. Reginster JY, Cooper C, Hochberg M, Pelletier JP, Rizzoli R, Kanis J, et al. Comments on the discordant recommendations for the use of symptomatic slow-acting drugs in knee osteoarthritis. Curr Med Res Opin. 2015;31(5):1041-5. https://doi. org/10.1185/03007995.2015.1027183.

15. Bruyere O, Cooper C, Al-Daghri NM, Dennison EM, Rizzoli R, Reginster JY. Inappropriate claims from non-equivalent medications in osteoarthritis: a position paper endorsed by the European Society for Clinical and Economic Aspects of Osteoporosis, Osteoarthritis and Musculoskeletal Diseases (ESCEO). Aging Clin Exp Res. 2017;30(2):111-7. https://doi.org/10.1007/s4052 0-017-0861-1.

16. Pelletier JP, Martel-Pelletier J. Diacerein-containing products: same risk of diarrhoea? Aging Clin Exp Res. 2018;30(4):411-2. https://doi.org/10.1007/s40520-018-0911-3.

17. Kingsbury SR, Gross HJ, Isherwood G, Conaghan PG. Osteoarthritis in Europe: impact on health status, work productivity and use of pharmacotherapies in five European countries. Rheumatology (Oxford). 2014;53(5):937-47. https://doi.org/10.1093/rheum atology/ket463.

18. Wilson N, Sanchez-Riera L, Morros R, Diez-Perez A, Javaid $\mathrm{MK}$, Cooper $\mathrm{C}$, et al. Drug utilization in patients with OA: a population-based study. Rheumatology (Oxford). 2015;54(5):860-7. https://doi.org/10.1093/rheumatology/keu403.

19. Pavelka K, Bruyere O, Cooper C, Kanis JA, Leeb BF, Maheu $\mathrm{E}$ et al. Diacerein: Benefits, risks and place in the management of osteoarthritis. An opinion-based report from the ESCEO. Drugs Aging. 2016;33(2):75-85. https://doi.org/10.1007/s4026 6-016-0347-4.

20. Fidelix TS, Macedo CR, Maxwell LJ, Fernandes Moca Trevisani V. Diacerein for osteoarthritis. Cochrane Database Syst Rev. 2014;2:CD005117. https://doi.org/10.1002/14651858.cd005 117.pub3.

21. Wandel S, Juni P, Tendal B, Nuesch E, Villiger PM, Welton NJ, et al. Effects of glucosamine, chondroitin, or placebo in patients with osteoarthritis of hip or knee: network meta-analysis. BMJ. 2010;341:c4675. https://doi.org/10.1136/bmj.c4675.

22. Cameron M, Chrubasik S. Oral herbal therapies for treating osteoarthritis. Cochrane Database Syst Rev. 2014(5):CD002947. https://doi.org/10.1002/14651858.cd002947.pub2.

23. Higgins JPT, Green S. Cochrane handbook for systematic reviews of interventions. Version 5.1.0 (updated March 2011). Available from: www.handbook.cochrane.org. The Cochrane Collaboration; 2011. Accessed 22 May 2017.

24. Moher D, Liberati A, Tetzlaff J, Altman DG, Group P. Preferred reporting items for systematic reviews and meta-analyses: the PRISMA statement. J Clin Epidemiol. 2009;62(10):1006-12. https://doi.org/10.1016/j.jclinepi.2009.06.005.

25. DerSimonian R, Laird N. Meta-analysis in clinical trials. Control Clin Trials. 1986;7(3):177-88.

26. Bradburn MJ, Deeks JJ, Berlin JA, Russell Localio A. Much ado about nothing: a comparison of the performance 
of meta-analytical methods with rare events. Stat Med. 2007;26(1):53-77. https://doi.org/10.1002/sim.2528.

27. Stijnen T, Hamza TH, Ozdemir P. Random effects meta-analysis of event outcome in the framework of the generalized linear mixed model with applications in sparse data. Stat Med. 2010;29(29):3046-67. https://doi.org/10.1002/sim.4040.

28. Normand SL. Meta-analysis: formulating, evaluating, combining, and reporting. Stat Med. 1999;18(3):321-59.

29. Higgins JP, Thompson SG, Deeks JJ, Altman DG. Measuring inconsistency in meta-analyses. BMJ. 2003;327(7414):557-60. https://doi.org/10.1136/bmj.327.7414.557.

30. Higgins JP, Thompson SG. Quantifying heterogeneity in a meta-analysis. Stat Med. 2002;21(11):1539-58. https://doi. org/10.1002/sim.1186.

31. Harbord RM, Egger M, Sterne JA. A modified test for smallstudy effects in meta-analyses of controlled trials with binary endpoints. Stat Med. 2006;25(20):3443-57. https://doi. org/10.1002/sim.2380.

32. Sterne JA, Sutton AJ, Ioannidis JP, Terrin N, Jones DR, Lau J, et al. Recommendations for examining and interpreting funnel plot asymmetry in meta-analyses of randomised controlled trials. BMJ. 2011;343:d4002. https://doi.org/10.1136/bmj.d4002.

33. Egger M, Davey Smith G, Schneider M, Minder C. Bias in meta-analysis detected by a simple, graphical test. BMJ. 1997;315(7109):629-34.

34. Guyatt G, Oxman AD, Akl EA, Kunz R, Vist G, Brozek $\mathrm{J}$ et al. GRADE guidelines: 1. Introduction-GRADE evidence profiles and summary of findings tables. J Clin Epidemiol. 2011;64(4):383-94. https://doi.org/10.1016/j.jclin epi.2010.04.026.

35. GRADEpro GDT: GRADEpro Guideline Development Tool [Software]. McMaster University, 2015 (developed by Evidence Prime, Inc.). Available from gradepro.org.: Evidence Prime, Inc.

36. Benito-Ruiz P, Camacho-Zambrano MM, Carrillo-Arcentales JN, Mestanza-Peralta MA, Vallejo-Flores CA, Vargas-Lopez SV et al. A randomized controlled trial on the efficacy and safety of a food ingredient, collagen hydrolysate, for improving joint comfort. International journal of food sciences and nutrition. 2009;60 Suppl 2(ccg, 9432922):99-113.

37. Bucsi L, Poor G. Efficacy and tolerability of oral chondroitin sulfate as a symptomatic slow-acting drug for osteoarthritis (SYSADOA) in the treatment of knee osteoarthritis. Osteoarthritis and Cartilage. 1998;6 Suppl A(9305697, cco):31-6.

38. Cahlin BJ, Dahlstrom L. No effect of glucosamine sulfate on osteoarthritis in the temporomandibular joints-a randomized, controlled, short-term study. Oral Surg Oral Med Oral Pathol Oral Radiol Endod. 2011;112(6):760-6.

39. Chopra A, Saluja M, Tillu G, Venugopalan A, Sarmukaddam S, Raut AK, et al. A randomized controlled exploratory evaluation of standardized ayurvedic formulations in symptomatic osteoarthritis knees: a Government of India NMITLI Project. Evid-based Complementary Altern Med. 2011;2011(101215021):724291.

40. Clegg DO, Reda DJ, Harris CL, Klein MA, O'Dell JR, Hooper $\mathrm{MM}$, et al. Glucosamine, chondroitin sulfate, and the two in combination for painful knee osteoarthritis. N Engl J Med. 2006;354(8):795-808. https://doi.org/10.1056/NEJMoa052771.

41. Esfandiari H, Pakravan M, Zakeri Z, Ziaie S, Pakravan P, Ownagh $V$. Effect of glucosamine on intraocular pressure: a randomized clinical trial. Eye (London, England). 2017;31(3):389-94.

42. Frestedt JL, Walsh M, Kuskowski MA, Zenk JL. A natural mineral supplement provides relief from knee osteoarthritis symptoms: a randomized controlled pilot trial. Nutr J. 2008;7(101152213):9.

43. Gabay C, Medinger-Sadowski C, Gascon D, Kolo F, Finckh A. Symptomatic effects of chondroitin 4 and chondroitin 6 sulfate on hand osteoarthritis: a randomized, double-blind, placebo-controlled clinical trial at a single center. Arthritis Rheum. 2011;63(11):3383-91.

44. Jiang JX, Yu S, Huang QR, Zhang XL, Zhang CQ, Zhou JL, et al. Collagen peptides improve knee osteoarthritis in elderly women: a 6-month randomized, double-blind, placebo-controlled study. Agro Food Industry Hi-Tech. 2014;25(2):19-23.

45. Kalman DS, Heimer M, Valdeon A, Schwartz H, Sheldon E. Effect of a natural extract of chicken combs with a high content of hyaluronic acid (Hyal-Joint) on pain relief and quality of life in subjects with knee osteoarthritis: a pilot randomized doubleblind placebo-controlled trial. Nutr J. 2008;7(101152213):3.

46. Kwoh CK, Roemer FW, Hannon MJ, Moore CE, Jakicic JM, Guermazi A, et al. Effect of oral glucosamine on joint structure in individuals with chronic knee pain: a randomized, placebocontrolled clinical trial. Arthritis Rheumatol. 2014;66(4):930-9.

47. Lugo JP, Saiyed ZM, Lane NE. Efficacy and tolerability of an undenatured type II collagen supplement in modulating knee osteoarthritis symptoms: a multicenter randomized, doubleblind, placebo-controlled study. Nutr J. 2016;15(101152213): 14 .

48. Moller I, Perez M, Monfort J, Benito P, Cuevas J, Perna C et al. Effectiveness of chondroitin sulphate in patients with concomitant knee osteoarthritis and psoriasis: a randomized, doubleblind, placebo-controlled study. Osteoarthr Cartilage. 2010;18 Suppl 1(9305697, cco):S32-40.

49. Noack W, Fischer M, Forster KK, Rovati LC, Setnikar I. Glucosamine sulfate in osteoarthritis of the knee. Osteoarthr Cartilage. 1994;2(1):51-9.

50. Pavelka K, Gatterova J, Olejarova M, Machacek S, Giacovelli G, Rovati LC. Glucosamine sulfate use and delay of progression of knee osteoarthritis: a 3-year, randomized, placebo-controlled, double-blind study. Arch Intern Med. 2002;162(18):2113-23.

51. Pavelka K, Trc T, Karpas K, Vitek P, Sedlackova M, Vlasakova $\mathrm{V}$, et al. The efficacy and safety of diacerein in the treatment of painful osteoarthritis of the knee: a randomized, multicenter, double-blind, placebo-controlled study with primary end points at two months after the end of a three-month treatment period. Arthritis Rheum. 2007;56(12):4055-64.

52. Pelletier JP, Yaron M, Haraoui B, Cohen P, Nahir MA, Choquette $\mathrm{D}$, et al. Efficacy and safety of diacerein in osteoarthritis of the knee: a double-blind, placebo-controlled trial. The Diacerein Study Group. Arthritis Rheum. 2000;43(10):2339-48.

53. Pujalte JM, Llavore EP, Ylescupidez FR. Double-blind clinical evaluation of oral glucosamine sulphate in the basic treatment of osteoarthrosis. Curr Med Res Opin. 1980;7(2):110-4.

54. Reginster JL, Group CI. CONCEPT provides robust evidence that chondroitin sulfate is superior to placebo and similar to celecoxib in the symptomatic management of osteoarthritis. Ann Rheum Dis. 2017. https://doi.org/10.1136/annrheumdis-2017-212165.

55. Roman-Blas JA, Castaneda S, Sanchez-Pernaute O, Largo R, Herrero-Beaumont G, Group CGCTS. Combined treatment with chondroitin sulfate and glucosamine sulfate shows no superiority over placebo for reduction of joint pain and functional impairment in patients with knee osteoarthritis: a six-month multicenter, randomized, double-blind, placebo-controlled clinical trial. Arthritis Rheumatol. 2017;69(1):77-85. https://doi. org/10.1002/art.39819.

56. Schauss AG, Stenehjem J, Park J, Endres JR, Clewell A. Effect of the novel low molecular weight hydrolyzed chicken sternal cartilage extract, BioCell Collagen, on improving osteoarthritis-related symptoms: a randomized, double-blind, placebocontrolled trial. J Agric Food Chem. 2012;60(16):4096-101.

57. Uebelhart D, Thonar EJ, Delmas PD, Chantraine A, Vignon E. Effects of oral chondroitin sulfate on the progression of knee osteoarthritis: a pilot study. Osteoarthr Cartilage. 1998;6 Suppl A(9305697, cco):39-46. 
58. Uebelhart D, Malaise M, Marcolongo R, de Vathaire F, Piperno $\mathrm{M}$, Mailleux E, et al. Intermittent treatment of knee osteoarthritis with oral chondroitin sulfate: a one-year, randomized, doubleblind, multicenter study versus placebo. Osteoarthr Cartilage. 2004;12(4):269-76.

59. Usha PR, Naidu MUR. Randomised, double-blind, parallel, placebo-controlled study of oral glucosamine, methylsulfonylmethane and their combination in osteoarthritis. Clin Drug Investig. 2004;24(6):353-63.

60. Zegels B, Crozes P, Uebelhart D, Bruyere O, Reginster JY. Equivalence of a single dose $(1200 \mathrm{mg})$ compared to a threetime a day dose $(400 \mathrm{mg})$ of chondroitin $4 \& 6$ sulfate in patients with knee osteoarthritis. Results of a randomized double blind placebo controlled study. Osteoarthr Cartilage. 2013;21(1):22-7. https://doi.org/10.1016/j.joca.2012.09.017.

61. Appelboom T, Schuermans J, Verbruggen G, Henrotin Y, Reginster JY. Symptoms modifying effect of avocado/soybean unsaponifiables (ASU) in knee osteoarthritis. A double blind, prospective, placebo-controlled study. Scand J Rheumatol. 2001;30(4):242-7.

62. Blotman F, Maheu E, Wulwik A, Caspard H, Lopez A. Efficacy and safety of avocado/soybean unsaponifiables in the treatment of symptomatic osteoarthritis of the knee and hip. A prospective, multicenter, three-month, randomized, double-blind, placebocontrolled trial. Rev Rheum Engl Ed. 1997;64(12):825-34.

63. Bourgeois P, Chales G, Dehais J, Delcambre B, Kuntz JL, Rozenberg S. Efficacy and tolerability of chondroitin sulfate $1200 \mathrm{mg} /$ day vs. chondroitin sulfate 3 x $400 \mathrm{mg}$ /day vs. placebo. Osteoarthritis and Cartilage. 1998;6 Suppl A(9305697, cco):25-30.

64. Cibere J, Kopec JA, Thorne A, Singer J, Canvin J, Robinson $\mathrm{DB}$, et al. Randomized, double-blind, placebo-controlled glucosamine discontinuation trial in knee osteoarthritis. Arthritis Rheum. 2004;51(5):738-45.

65. Das A Jr, Hammad TA. Efficacy of a combination of FCHG49 glucosamine hydrochloride, TRH122 low molecular weight sodium chondroitin sulfate and manganese ascorbate in the management of knee osteoarthritis. Osteoarthr Cartilage. 2000;8(5):343-50.

66. Dougados M, Nguyen M, Berdah L, Mazieres B, Vignon E, Lequesne M. Evaluation of the structure-modifying effects of diacerein in hip osteoarthritis: ECHODIAH, a three-year, placebo-controlled trial. Evaluation of the Chondromodulating Effect of Diacerein in OA of the Hip. Arthritis Rheum. 2001;44(11):2539-47.

67. Drovanti A, Bignamini AA, Rovati AL. Therapeutic activity of oral glucosamine sulfate in osteoarthrosis: a placebo-controlled double-blind investigation. Clin Ther. 1980;3(4):260-72.

68. Fransen M, Agaliotis M, Nairn L, Votrubec M, Bridgett L, Su $\mathrm{S}$, et al. Glucosamine and chondroitin for knee osteoarthritis: a double-blind randomised placebo-controlled clinical trial evaluating single and combination regimens. Ann Rheum Dis. 2015;74(5):851-8. https://doi.org/10.1136/annrheumdis-2013203954.

69. Giordano N, Fioravanti A, Papakostas P, Montella A, Giorgi G, Nuti R. The efficacy and tolerability of glucosamine sulfate in the treatment of knee osteoarthritis: a randomized, double-blind, placebo-controlled trial. Curr Ther Res Clin Exp. 2009;70(3):18596. https://doi.org/10.1016/j.curtheres.2009.05.004.

70. Herrero-Beaumont G, Ivorra JA, Del Carmen Trabado M, Blanco FJ, Benito P, Martin-Mola E, et al. Glucosamine sulfate in the treatment of knee osteoarthritis symptoms: a randomized, double-blind, placebo-controlled study using acetaminophen as a side comparator. Arthritis Rheum. 2007;56(2):555-67. https:// doi.org/10.1002/art.22371.

71. Hughes R, Carr A. A randomized, double-blind, placebocontrolled trial of glucosamine sulphate as an analgesic in osteoarthritis of the knee. Rheumatology (Oxford, England). 2002;41(3):279-84.

72. Kahan A, Uebelhart D, De Vathaire F, Delmas PD, Reginster JY. Long-term effects of chondroitins 4 and 6 sulfate on knee osteoarthritis: the study on osteoarthritis progression prevention, a two-year, randomized, double-blind, placebo-controlled trial. Arthritis Rheum. 2009;60(2):524-33. https://doi.org/10.1002/ art.24255.

73. Kumar S, Sugihara F, Suzuki K, Inoue N, Venkateswarathirukumara S. A double-blind, placebo-controlled, randomised, clinical study on the effectiveness of collagen peptide on osteoarthritis. J Sci Food Agric. 2014. https://doi.org/10.1002/jsfa.6752.

74. Lequesne M, Berdah L, Gerentes I. Efficacy and tolerance of diacerhein in the treatment of gonarthrosis and coxarthrosis. La Revue du praticien. 1998;48(17 Suppl):S31-5.

75. Lequesne M, Maheu E, Cadet C, Dreiser RL. Structural effect of avocado/soybean unsaponifiables on joint space loss in osteoarthritis of the hip. Arthritis Rheum. 2002;47(1):50-8.

76. Maheu E, Mazieres B, Valat JP, Loyau G, Le Loet X, Bourgeois $\mathrm{P}$, et al. Symptomatic efficacy of avocado/soybean unsaponifiables in the treatment of osteoarthritis of the knee and hip: a prospective, randomized, double-blind, placebo-controlled, multicenter clinical trial with a six-month treatment period and a two-month followup demonstrating a persistent effect. Arthritis Rheum. 1998;41(1):81-91. https://doi.org/10.1002/15290131(199801)41:1\%3c81:AID-ART11\%3e3.0.CO;2-9.

77. Maheu E, Cadet C, Marty M, Moyse D, Kerloch I, Coste P, et al. Randomised, controlled trial of avocado-soybean unsaponifiable (Piascledine) effect on structure modification in hip osteoarthritis: the ERADIAS study. Ann Rheum Dis. 2014;73(2):376-84. https://doi.org/10.1136/annrheumdis-2012-202485.

78. Mathieu P. Radiological progression of internal femorotibial osteoarthritis in gonarthrosis: effect of chondroitin sulfates ACS4ACS6 as a structure modifying drug in knee OA (SMOAD). Presse Medicale. 2002;31(29):1386-90.

79. Mazieres B, Loyau G, Menkes CJ, Valat JP, Dreiser RL, Charlot $\mathrm{J}$ et al. [Chondroitin sulfate in the treatment of gonarthrosis and coxarthrosis. 5-months result of a multicenter double-blind controlled prospective study using placebo]. Rev Rhum Mal Osteoartic. 1992;59(7-8):466-72.

80. Mazieres B, Combe B, Van Phan A, Tondut J, Grynfeltt M. Chondroitin sulfate in osteoarthritis of the knee: a prospective, double blind, placebo controlled multicenter clinical study. $\mathbf{J}$ Rheumatol. 2001;28(1):173-81.

81. Mazieres B, Hucher M, Zaim M, Garnero P. Effect of chondroitin sulphate in symptomatic knee osteoarthritis: a multicentre, randomised, double-blind, placebo-controlled study. Ann Rheum Dis. 2007;66(5):639-45. https://doi.org/10.1136/ard.2006.05989 9.

82. McAlindon TE, Nuite M, Krishnan N, Ruthazer R, Price LL, Burstein D, et al. Change in knee osteoarthritis cartilage detected by delayed gadolinium enhanced magnetic resonance imaging following treatment with collagen hydrolysate: a pilot randomized controlled trial. Osteoarthr Cartilage. 2011;19(4):399-405.

83. Michel BA, Stucki G, Frey D, De Vathaire F, Vignon E, Bruehlmann P, et al. Chondroitins 4 and 6 sulfate in osteoarthritis of the knee: a randomized, controlled trial. Arthritis Rheum. 2005;52(3):779-86. https://doi.org/10.1002/art.20867.

84. Nakagawa Y, Mukai S, Yamada S, Matsuoka M, Tarumi E, Hashimoto T, et al. Short-term effects of highly-bioavailable curcumin for treating knee osteoarthritis: a randomized, doubleblind, placebo-controlled prospective study. J Orthopaedic Sci. 2014;19(6):933-9. 
85. Nguyen M, Dougados M, Berdah L, Amor B. Diacerein in the treatment of osteoarthritis of the hip. Arthritis Rheum. 1994;37(4):529-36.

86. Panahi Y, Rahimnia A-R, Sharafi M, Alishiri G, Saburi A, Sahebkar A. Curcuminoid treatment for knee osteoarthritis: a randomized double-blind placebo-controlled trial. Phytotherapy Res. 2014;28(11):1625-31.

87. Pham T, Le Henanff A, Ravaud P, Dieppe P, Paolozzi L, Dougados M. Evaluation of the symptomatic and structural efficacy of a new hyaluronic acid compound, NRD101, in comparison with diacerein and placebo in a 1 year randomised controlled study in symptomatic knee osteoarthritis. Ann Rheum Dis. 2004;63(12):1611-7.

88. Railhac JJ, Zaim M, Saurel AS, Vial J, Fournie B. Effect of 12 months treatment with chondroitin sulfate on cartilage volume in knee osteoarthritis patients: a randomized, double-blind, placebo-controlled pilot study using MRI. Clin Rheumatol. 2012;31(9):1347-57.

89. Reginster JY, Deroisy R, Rovati LC, Lee RL, Lejeune E, Bruyere $\mathrm{O}$, et al. Long-term effects of glucosamine sulphate on osteoarthritis progression: a randomised, placebo-controlled clinical trial. Lancet. 2001;357(9252):251-6. https://doi.org/10.1016/ S0140-6736(00)03610-2.

90. Rindone JP, Hiller D, Collacott E, Nordhaugen N, Arriola G. Randomized, controlled trial of glucosamine for treating osteoarthritis of the knee. West J Med. 2000;172(2):91-4.

91. Rozendaal RM, Koes BW, van Osch GJVM, Uitterlinden EJ, Garling EH, Willemsen SP, et al. Effect of glucosamine sulfate on hip osteoarthritis: a randomized trial. Ann Intern Med. 2008;148(4):268-77.

92. Shin K, Kim JW, Moon KW, Yang JA, Lee EY, Song YW, et al. The efficacy of diacerein in hand osteoarthritis: a double-blind, randomized, placebo-controlled study. Clin Ther. 2013;35(4):431-9.

93. Srivastava S, Saksena AK, Khattri S, Kumar S, Dagur RS. Curcuma longa extract reduces inflammatory and oxidative stress biomarkers in osteoarthritis of knee: a four-month, double-blind, randomized, placebo-controlled trial. Inflammopharmacology. 2016;24(6):377-88.

94. Stančík R, Zvarka J, Hlaváč M, Kubinec V, Rovenský J. Collagen type I in the treatment of painful osteoarthritis of the knee. Reumatologia. 2012;50(5):390-6. https://doi.org/10.5114/ reum.2012.31397.

95. Vignon E. Results of ECHODIAH study in hip osteoarthritis. [French]. Resultats de l'essai therapeutique ECHODIAH dans l'arthrose de hanche. 2002;31(1 II):7.

96. Wildi LM, Raynauld JP, Martel-Pelletier J, Beaulieu A, Bessette L, Morin F, et al. Chondroitin sulphate reduces both cartilage volume loss and bone marrow lesions in knee osteoarthritis patients starting as early as 6 months after initiation of therapy: a randomised, double-blind, placebo-controlled pilot study using MRI. Ann Rheum Dis. 2011;70(6):982-9. https://doi. org/10.1136/ard.2010.140848.
97. Zenk Jl HTRKMA. The effects of milk protein concentrate on the symptoms of osteoarthritis in adults: An exploratory, randomized, double-blind, placebo-controlled trial. 2002;63(7):430.

98. Zeng C, Wei J, Li H, Wang YL, Xie DX, Yang T, et al. Effectiveness and safety of Glucosamine, chondroitin, the two in combination, or celecoxib in the treatment of osteoarthritis of the knee. Sci Rep. 2015;5:16827. https://doi.org/10.1038/srep16827.

99. Christiansen BA, Bhatti S, Goudarzi R, Emami S. Management of osteoarthritis with avocado/soybean unsaponifiables. Cartilage. 2015;6(1):30-44. https://doi.org/10.1177/1947603514 554992.

100. Msika P, Baudouin C, Saunois A, Bauer T. Avocado/soybean unsaponifiables, ASU EXPANSCIENCE, are strictly different from the nutraceutical products claiming ASU appellation. Osteoarthritis Cartilage. 2008;16(10):1275-6. https://doi. org/10.1016/j.joca.2008.02.017.

101. Olivier P, Montastruc JL, Reseau francais des centres regionaux de p. [Post-marketing safety profile of avocado-soybean unsaponifiables]. Presse Med. 2010;39(10):e211-6. https://doi. org/10.1016/j.lpm.2010.01.013.

102. Nicolas P, Tod M, Padoin C, Petitjean O. Clinical pharmacokinetics of diacerein. Clin Pharmacokinet. 1998;35(5):347-59. https ://doi.org/10.2165/00003088-199835050-00002.

103. Renan X, Lepage M, Connan D, Carlhant D, Riche C, Verger $\mathrm{P}$, et al. Case report of fatal hepatitis from diacerein. Therapie. 2001;56(2):190-1.

104. Vial T, Mille R, Bory RM, Evreux JC. Acute hepatitis asociated with ingestion of of diacerein. Gastroenterol Clin Biol. 1997;21(10):795-6.

105. Blondon H, Bikart I, Bergmann JF. Severe diarrhea with hypokalemia attributed to diacetylrhein. Gastroenterol Clin Biol. 1995;19(10):851-2.

106. EMA. European Medicines Agency. Assessment report for diacerein containing medicinal products. EMA/527347/2014. 2014. http://www.ema.europa.eu/docs/en_GB/document_libra ry/Referrals_document/Diacerein/European_Commission_final _decision/WC500173145.pdf. Accessed 27 Apr 2018.

107. Cardoso CRL, Leite NC, Carlos FO, Loureiro AA, Viegas BB, Salles GF. Efficacy and safety of diacerein in patients with inadequately controlled type 2 diabetes: a randomized controlled trial. Diabetes Care. 2017;40(10):1356-63. https://doi.org/10.2337/ dc17-0374.

108. Piovesan F, Tres GS, Moreira LB, Andrades ME, Lisboa HK, Fuchs SC. Effect of diacerein on renal function and inflammatory cytokines in participants with type 2 diabetes mellitus and chronic kidney disease: a randomized controlled trial. PLoS One. 2017;12(10):e0186554. https://doi.org/10.1371/journ al.pone. 0186554 .

109. Bu T, Wang C, Meng Q, Huo X, Sun H, Sun P, et al. Hepatoprotective effect of rhein against methotrexate-induced liver toxicity. Eur J Pharmacol. 2018;834:266-73. https://doi.org/10.1016/j. ejphar.2018.07.031.

\section{Affiliations}

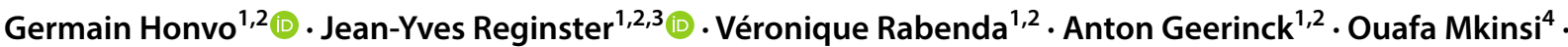 Alexia Charles $\mathrm{s}^{1,2} \cdot$ Rene Rizzoli $^{2,5} \cdot$ Cyrus Cooper $^{2,6,7} \cdot$ Bernard Avouac $^{1} \cdot$ Olivier Bruyère $^{1,2} \mathbb{C}$}

Germain Honvo

germain.honvo@uliege.be

Jean-Yves Reginster

jyreginster@uliege.be
Véronique Rabenda

veronique.rabenda@uliege.be

Anton Geerinck

anton.geerinck@uliege.be 
Ouafa Mkinsi

omkinsi@hotmail.fr

Alexia Charles

alexia.charles@uliege.be

Rene Rizzoli

Rene.Rizzoli@unige.ch

Cyrus Cooper

cc@mrc.soton.ac.uk

Bernard Avouac

bernardavouac@sfr.fr

Olivier Bruyère

olivier.bruyere@uliege.be

1 Department of Public Health, Epidemiology and Health Economics, University of Liège, Liège, Belgium

2 WHO Collaborating Centre for Public Heath Aspects of Musculoskeletal Health and Aging, Liège, Belgium
3 Chair for Biomarkers of Chronic Diseases, Biochemistry Department, College of Science, King Saud University, Riyadh, Kingdom of Saudi Arabia

4 Rheumatology Department, IBN ROCHD University Hospital, Casablanca, Morocco

5 Division of Bone Diseases, Geneva University Hospitals and Faculty of Medicine, Geneva, Switzerland

6 MRC Lifecourse Epidemiology Unit, University of Southampton, Southampton General Hospital, Southampton, UK

7 National Institute for Health Research (NIHR) Musculoskeletal Biomedical Research Unit, University of Oxford, Oxford, UK 